\title{
How might Canadian women talk about peri-coital contraception?
}

\author{
Simone N. Parniak \\ Supervisor Dr. Angel M. Foster DPhil, MD, AM \\ Institute of Feminist and Gender Studies \\ Faculty of Social Sciences \\ University of Ottawa \\ August 2015
}

Submitted to the University of Ottawa in partial fulfillment of the requirements of the degree of Master of Arts in Women's Studies

(C) Simone N. Parniak, Ottawa, Canada, 2015 


\begin{abstract}
$\underline{\text { Abstract }}$
The peri-coital contraceptive pill is a potential method for pregnancy prevention that could be taken in a period before or after unprotected sexual intercourse. However, uptake of a new contraceptive method relies on accessible terminology and frameworks with which to discuss it. I conducted seven focus group discussions across Canada to understand how women talk about different reproductive health technologies, explore the ways these discourses influence language and frameworks women use to talk about peri-coital contraceptives, and identify perceptions of and concerns about this potential method. Women thought the peri-coital contraceptive pill would be a valuable addition to current contraception. They disliked the name "peri-coital"; although some participants created more resonant names related to unique aspects of this method, many found it challenging to clearly discuss the method with existing language for contraception. Concerted effort to develop terminology that is clearer may help facilitate the eventual introduction of this new contraceptive method in Canada and beyond.
\end{abstract}




\section{$\underline{\text { Acknowledgements }}$}

First, I would like to thank the Society of Family Planning for funding this project.

I would like to express gratitude to my supervisor, Dr. Angel M Foster, for providing me with this incredible opportunity. You introduced me to the world of research - I have learned so much from you every step of this journey and I am eternally grateful for that.

I would like to thank my thesis advisory committee members, Dr. Shoshana Magnet and Dr. Ruksana Ahmed for their guidance throughout this process and offering their expertise to the development of this thesis.

Additionally, I would like to extend my thanks to Dr. Christine Kelly and Dr. Christabelle Sethna for wonderful research opportunities and the mentorship I have received over the past two years.

Thank you to all the women who participated in my research - without them this truly would not have been possible. I would also like to express my appreciation to all the community organizations and university groups who showed an interest and spread the word about my research.

To my friends at the office - thank you for the support, edits and kind words. Thank you to Jane for being an amazing long distance bestie. A special thanks to Kathryn who is a wonderful friend and colleague. I am eternally grateful for our weekly coffee dates.

Thank you AP for your patience and for being my anchor when I felt lost in a sea of academia.

Finally, to my Mum who gave me feminist roots and taught me to be true to myself. Thank you for your unconditional support and words of encouragement, and for always being proud of me. I love you. 


\section{Table of Contents}

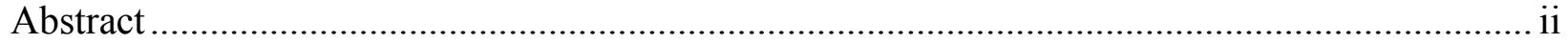

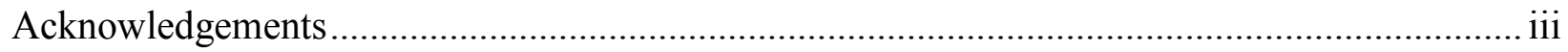

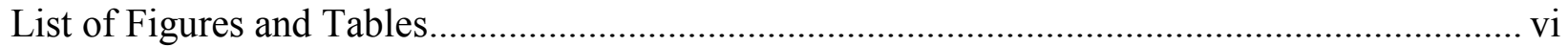

List of Appendices ......................................................................................................... vi

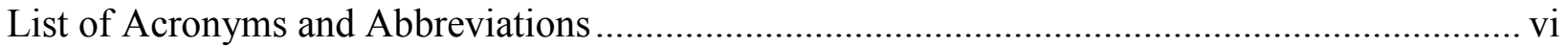

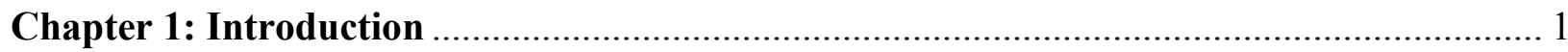

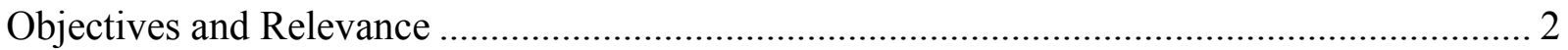

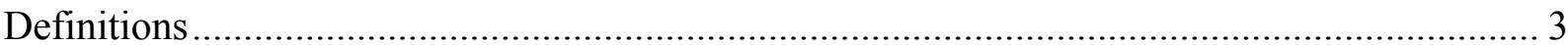

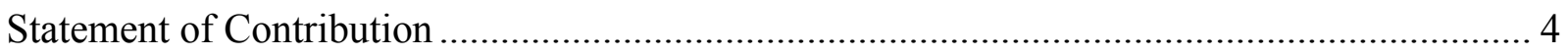

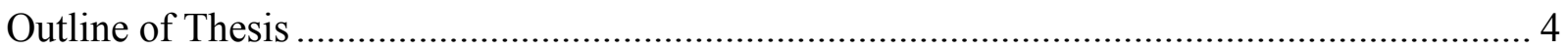

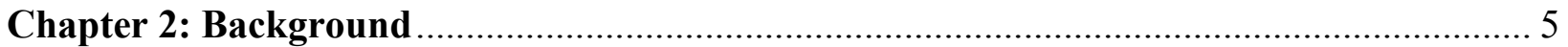

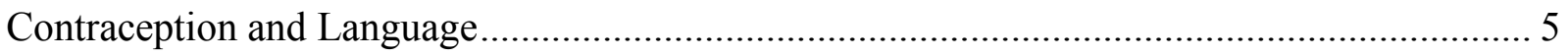

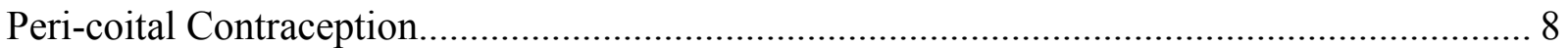

Chapter 3: Theoretical Framework .......................................................................... 14

A Brief History of Contraception in Canada ................................................................. 14

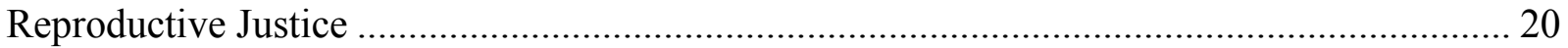

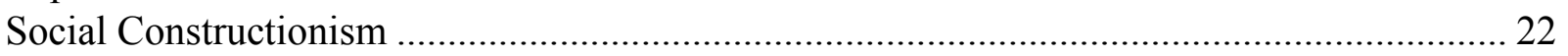

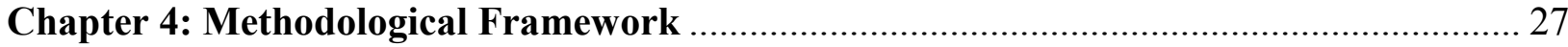

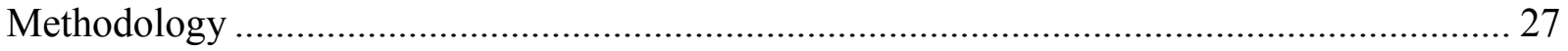

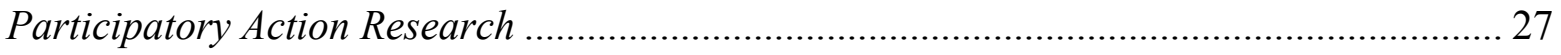

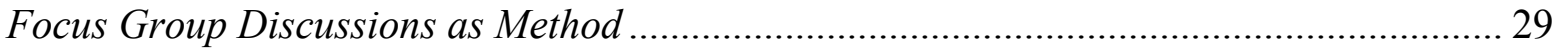

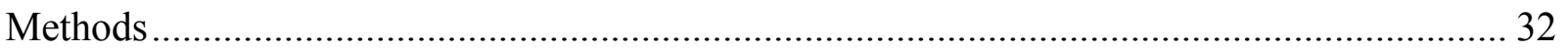

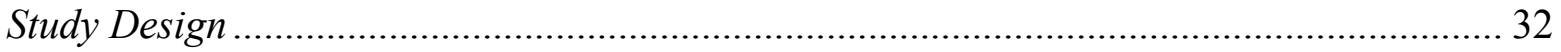

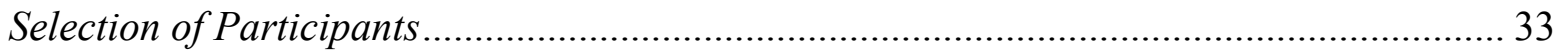

Focus Group Discussion Process ......................................................................... 34

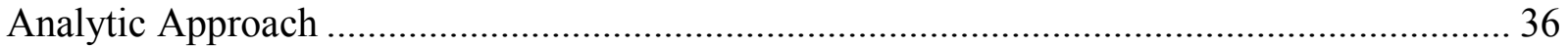

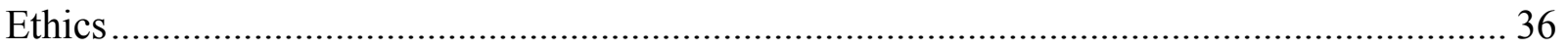

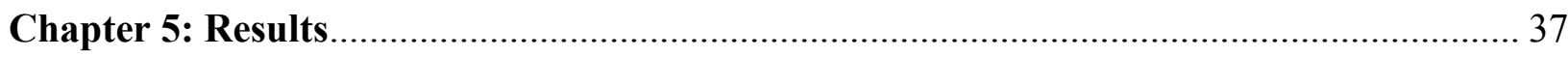

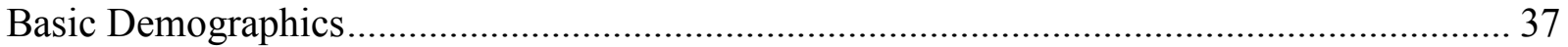

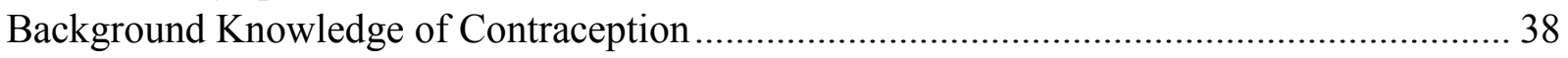

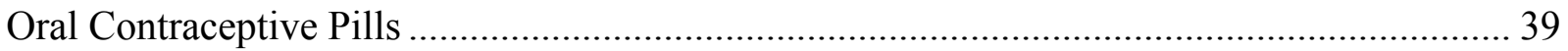

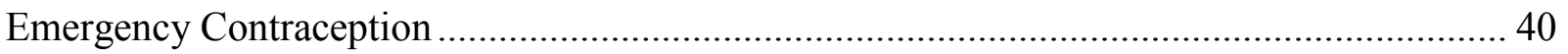

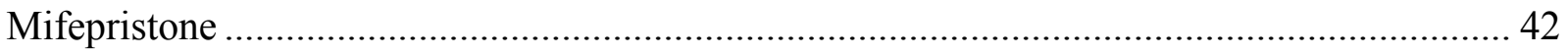

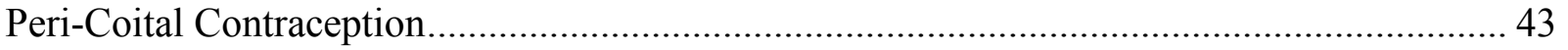

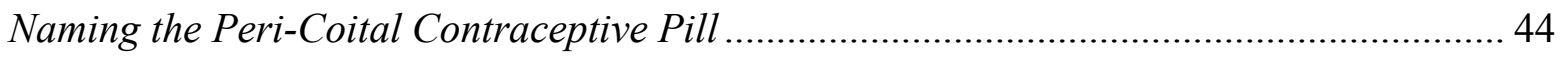

Differentiation of Contraceptive Methods ........................................................................... 45

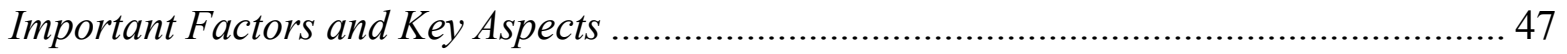

Packaging the Peri-Coital Contraceptive Pill................................................................. 48

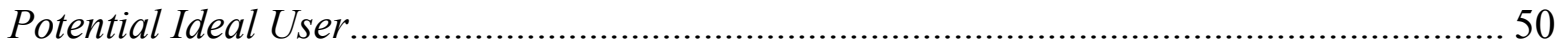

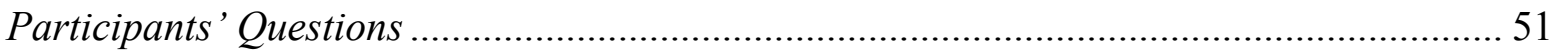

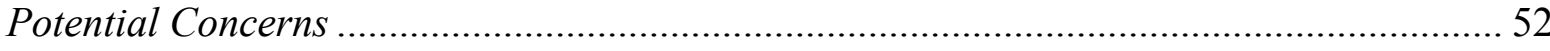

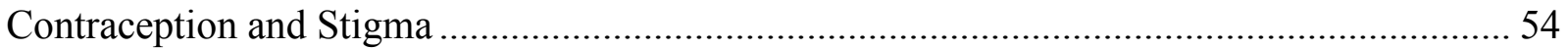




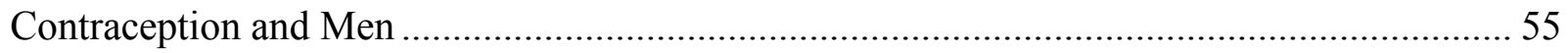

Misperceptions about Contraception .............................................................................. 56

Canadian Reproductive Health Issues ............................................................................ 58

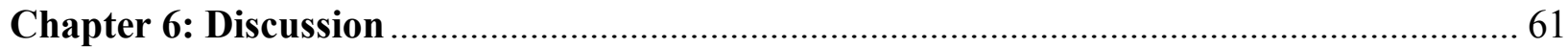

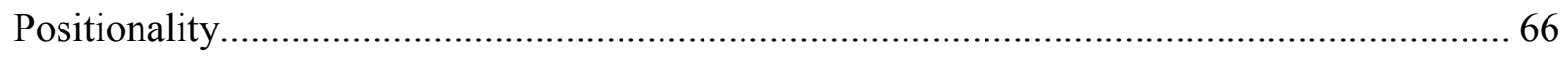

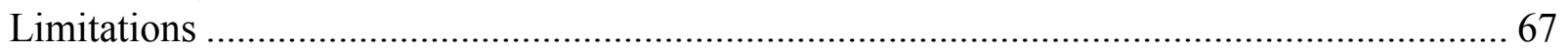

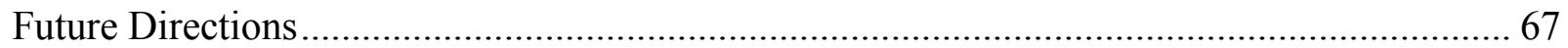

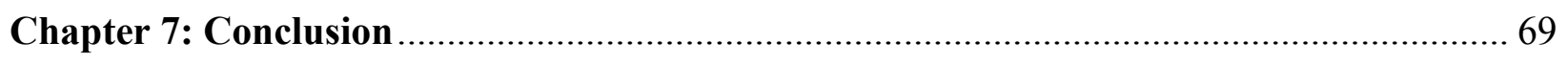

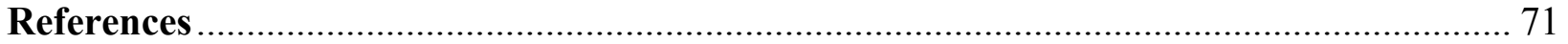




\section{$\underline{\text { List of Figures and Tables }}$}

Table 1: Composition of FGDs (p. 38)

Figure 1: Chosen names for the peri-coital contraceptive pill (p. 45)

\section{$\underline{\text { List of Appendices }}$}

Appendix A: Research Ethics Board approval letter

\section{List of Acronyms and Abbreviations}

FGD Focus group discussion

IUD Intrauterine device

LNG-EC Levonorgestrel emergency contraception

OCP Oral contraceptive pill

PAR Participatory action research

PI Principal investigator

STI Sexually transmitted infection

WHO World Health Organization 


\section{Chapter 1: Introduction}

By 2050 , researchers predict that worldwide 150 million women will have an unmet need for contraception due to lack of access, availability, and acceptability of contraceptive methods (RamaRao, Sitruk-Ware, \& Townsend, 2008). In fact, within the United States alone, half of unintended pregnancies occur in women who are using contraception (Jensen, 2011). Whether these pregnancies are a result of inconsistent use or non-use, there is an evident gap in reproductive health as the contraceptive needs of women and couples are not being met. This is particularly true for women who have infrequent sexual intercourse and do not necessarily need contraception every day, but certainly do when sexual intercourse occurs. Women who are the most at risk for unintended pregnancy are those who have sexual intercourse once a week or less (Frost, Singh, \& Finer, 2007).

In recent years there has been renewed effort to develop a peri-coital contraceptive, a progestin-only contraceptive pill that could be used to prevent pregnancy when taken either before or after sexual intercourse. Clinical trials are currently underway to investigate this pill's efficacy and acceptability. Lessons learned from the global experience of progestin-only postcoital pills suggest that many women would desire a peri-coital alternative. Indeed, there appears to be global enthusiasm for a pill-based contraceptive method that is reversible, inexpensive, effective, and intuitive (Keesbury, Morgan, \& Owino, 2011; Lerkiabundit \& Reanmongkol, 2000; Opuku \& Kwaununu, 2011). Taking a pill in a limited window either before or after sexual intercourse may address these factors, especially among women who only have occasional penile-vaginal intercourse. This method has the potential to fill a significant gap in current hormonal contraceptive options. 
There remains much work to be done to develop such a technology. Yet one important aspect of the development of this technology is how to talk about it; the term "peri-coital" is generally inaccessible to most potential users of the medication. Medical terminologies have a history of causing confusion amongst health professionals as well as the general public. There are many examples of reproductive health technologies that have been undermined by terminology, where the language used to describe the method or device causes misinformation, thus influencing uptake. In order to ensure uptake of emerging methods of contraception, potential users need to have an understanding of both the terminology used to refer to the technology and also a clear, concise way of discussing the methods in different contexts.

\section{Objectives and Relevance}

This thesis focuses on the language and frameworks Canadian women use to talk about current and emerging contraceptive methods. Specifically, this study comprises focus group discussions (FGDs) with women in seven cities across Canada to explore the following research questions:

a) How do women talk about different available contraception and abortion technologies?

b) How do these discourses influence the language and frameworks women use to talk about the peri-coital contraceptive pill?

c) What are Canadian women's perceptions of and concerns about this potential contraceptive method?

This research addresses how women's personal experiences with contraception, as well as external influences, inform the language they use to talk about current and emerging 
contraceptive methods. This research also provides insight into whether the desire for a new method of contraceptive exists in Canada and with the use of FGDs, my research engages women directly in the development of language and frameworks surrounding peri-coital contraception in order to potentially maximize comprehension and clarity.

\section{Definitions}

The key contraceptive and abortion methods that are discussed through this thesis are defined by the following terms. I based these definitions on the medical and scientific literature and provided these definitions to participants in the FGDs, as needed.

- Daily Oral Contraceptive Pill (OCP): A pill comprised of a progestin or a combination of an estrogen and a progestin that is taken once each day in order to prevent pregnancy.

- Levonorgestrel Emergency Contraception (LNG-EC): $1.5 \mathrm{mg}$ of progestin that can be taken up to 120 hours after unprotected or underprotected intercourse in order to prevent pregnancy. Available brands may be comprised of one or two pills.

- Mifepristone: A pill that can be taken up to 9 weeks' gestation in order to terminate an existing pregnancy but is not yet available in Canada. ${ }^{1}$ Mifepristone is used in conjunction with a second medication for early abortion.

- Peri-coital Contraceptive Pill: A hypothetical pill that can be taken in a window of 24 hours before to 24 hours after sexual intercourse as often as needed in any given month or cycle. Its hypothetical composition was described as $0.75 \mathrm{mg}$ of a progestin. As reference

\footnotetext{
${ }^{1}$ Health Canada approved mifepristone in July 2015 but we expect it will take 12-18 months for it to become available. At the time of data collection, mifepristone had not been approved. However, a method of medication abortion, methotrexate followed by misoprostol, has been available in Canada for some time and can be used up to 7 weeks gestation to terminate a pregnancy. This method was also discussed in the FGDs.
} 
this is half the amount included in LNG-EC but more progestin than what is in OCPs (combined or progestin-only)

\section{Statement of Contribution}

As the Principal Investigator (PI) of the study, I completed this study in partial fulfillment of the requirements for the Master of Arts in Feminist and Gender Studies program at the University of Ottawa. Consistent with my role as the PI, I was responsible for all phases of the project, including study design, data collection and analysis, and interpretation of the findings. My supervisor, Dr. Angel M. Foster, supervised the overall project and contributed to all phases of the study including conceptualization and design of the study, development of the study instruments, data analysis, and interpretation of the findings.

\section{Outline of Thesis}

In Chapter 2 I explore the confusing nature of language in reproductive health and provide more information about the peri-coital contraceptive pill. Next, in Chapter 3 I present the theoretical concepts of social constructionism, discourse, and reproductive justice and situate them within the context of this thesis. In Chapter 4 I describe the methodology that I used for this project. In Chapter 5 I share the key findings from the FGDs and in Chapter 6 I compare these results to a growing body of literature and explore larger implications of this project. Finally, I conclude by summarizing my thesis and offering recommendations for future study. 


\section{Chapter 2: Background}

In this chapter I present literature on two important aspects of this thesis. First, I will explore the confusing nature of language in healthcare, particularly in reproductive health, its different sources, and how this confusion impacts patients. I will then provide a review of the peri-coital contraceptive method's history and the potential for (re)introducing this method as a contraceptive option.

\section{Contraception and Language}

Language is an important part of understanding and communicating about various aspects of healthcare. Terminologies can help patients define and categorize diagnoses and treatments. However, the literature demonstrates that there exists much confusion surrounding medical terminology which may hamper a patient's understanding. In a study of diabetes appointments, researchers reported that nearly $81 \%$ of appointments contained medical jargon that the patient did not understand and on average, four unclear terms were used per visit with a physician (Castro et al., 2007). The majority of jargon was used when doctors were making recommendations or providing health education, aspects of the appointment which require patients' understanding in order to be beneficial. Doctors are also far more likely to use medical language when talking to both patients and other healthcare workers, whereas patients and nursing staff are more likely to use common everyday language in the healthcare setting (Bourhis, 1989). Another study showed that healthcare workers and patients chose incorrect definitions when referring to diagnoses (Hadlow \& Pitts, 1991). This may inhibit clear communication between the patient and the physician if the physician gives a diagnosis without explanation and the patient confuses it with something else. 
Sexual and reproductive health also have inconsistent terminology that can cause confusion. An issue that is particularly relevant to reproductive health is terminology that has been created outside of the medical community. Many anti-choice activists in the US have created terms for political purposes that are incorrect. For example, removal of a fetus after 24 weeks should not be clinically defined as an "abortion", but often is cited as such within the antichoice movement (Grimes \& Stuart, 2010). Grimes \& Stuart (2010) call for the use of terms such as "termination of a pregnancy" or the medically correct "intact dilation and evacuation" to describe procedures performed later in a pregnancy. Another term created by the anti-choice community is "partial-birth abortion", used to describe a dilation and extraction procedure (Grimes \& Stuart, 2010). By using both "birth" and "abortion", the result is a term that is somewhat of a contradiction but is used as a political tool by activists to evoke negative imagery. Because the terms have become well-known, they are adopted by the media and the general public.

Abortion causes further confusion when it is preceded by the terms "medical" and "surgical". In their 2004 commentary Weitz, Foster, Ellertson, Grossman, and Stewart noted that "medical abortion" promotes the idea that the abortion is something medically indicated and done in a healthcare setting, as opposed to an "illegal abortion". Often, a "medical abortion" is used to describe an abortion procured by the use of medication and the author proposes the use of "medication abortion" as a less confusing term. As for a "surgical abortion", this invokes images of a hospital setting and a long procedure and recovery period performed by a surgeon, when in reality, the modifier refers to simple procedures occurring in the first trimester that can be safely performed by a range of providers (Weitz et al., 2004). The use of "aspiration abortion" is a far clearer term to describe these procedures. 
A study by researchers in the US found examples of the media using incorrect terminology to refer to reproductive technologies. Pruitt and Mullen found that terms that are completely different are often used interchangeably causing the general population to be misinformed (2005). They made this conclusion as they analyzed a number of newspaper articles written between 1992 and 2002. In these articles, there were a number of errors such as referring to the abortifacient mifepristone as the "morning-after pill" and referring to LNG-EC as the "day-after pill" (Pruitt \& Mullen, 2005). Nearly half of the articles studied had at least one term used incorrectly. These errors were even found in headlines, such as "Morning-after pill induces abortion" (Pruitt \& Mullen, 2005).

These errors may have serious effects on the public's knowledge of reproductive health technologies. Misinformation in the general public has been documented in a series of studies involving an interactive website called www.not-2-late.com (Wynn \& Trussell, 2005; Wynn, Foster, \& Trussell, 2009; Wynn, Foster, \& Trussell, 2010). This website invites individuals to write in and ask questions regarding sexual intercourse and reproductive health. The studies found that individuals asking questions used the term "the pill" to refer to both LNG-EC and the oral contraceptive pill, demonstrating the confusion behind the terminology commonly heard. As well, there is an existing pattern that "protected sex" pertains only to sex with a condom, even if a woman is using an oral contraceptive or other contraceptive method (Wynn et al., 2009).

A great deal of confusion surrounds LNG-EC. For example, women writing to the website referred to progestin only emergency contraception as "Plan B", the "morning after pill", "after sex" pill, and even "emergency anti-pregnancy pill" (Wynn et al., 2010). A number of women confused LNG-EC with medication abortion and wondered if LNG-EC could in fact terminate an existing pregnancy (Wynn et al., 2009). Women reported in the questions that 
LNG-EC would only be successful is used immediately, within 12 hours of intercourse, or up to 72 hours after sex (Wynn et al., 2010). Research has shown that LNG-EC is actually effective up to 120 hours after unprotected sexual intercourse (Wynn et al., 2010). This misinformation about timeframe of use can result in women not taking the medication because it is no longer "the morning after" and they believes it has no chance of working. This demonstrates possible misperceptions that can arise if the public is presented with incorrect or confusing information surrounding reproductive technologies. The fact that many people used this website to make inquiries regarding their sexual health provides suggests there is a lack of clear communication between physician and patient and that often the language provided is misunderstood by the patient (Wynn \& Trussell, 2005).

The literature reveals that there is a clear lack of consistency in medical terminology, specifically in reproductive health. Potentially stemming from multiple sources, the result of the inconsistency is often confusion when discussing sensitive subjects that require clear comprehension. The lack of understanding leads patients, especially women, to be misinformed and may cause issues for those making choices about their reproductive health. By clarifying definitions and creating consensus terminology, individuals may be better able to make fully informed decisions regarding new medical technologies that exist in the reproductive field.

\section{Peri-coital Contraception}

The study of levonorgestrel as a peri-coital oral contraceptive began in the 1970-80s, with a number of trials that took place in Europe and South America (World Health Organization (WHO) Task Force on Postovulatory Methods of Fertility Regulation, 2000). These trials examined the effectiveness of preventing pregnancy by having a group of women use a dose of 
levonorgestrel as a post-coital contraception method. The trials ranged from a few months to a few years of repeated post-coital levonorgestrel use (Raymond, Halpern, \& Lopez, 2011). On average, the women in the studies had sexual intercourse four times a month (Halpern, Raymond, \& Lopez, 2010). The doses were different among the trials although the majority used $0.75 \mathrm{mg}$ levonorgestrel per dose (Halpern et al., 2010). One of the issues with these early studies was the complicated instructions on when to take the pill after intercourse. One study recommended that one $0.75 \mathrm{mg}$ dose be taken no later than 8 hours after intercourse and then a second pill be taken 24 hours later (Chang-hai, Yong-en, Jian-qiu, \& Van Look, 1991). Yet a different study instructed a dose no later than one hour after intercourse and then if sexual intercourse occurred again after three or more hours, another pill would be taken an hour after that act (WHO Task Force, 2000). Other studies had different rules for when the first pill should be taken and when the second should follow. Only one trial, led by Echeverry and Sarria (1974), used a one dose protocol (as cited in Raymond et al., 2011). Some studies set limits on how many doses could be taken in a month while others did not (Raymond et al., 2011).

These various studies found that peri-coital levonorgestrel was quite effective in preventing pregnancy. This was shown using the Pearl Index, the ratio of failures (pregnancies) to exposure in women-years (cycles) multiplied by 100 (Trussell, 1991). The average Pearl Index for 0.75 mg levonorgestrel studies was between 4.9-5.1 pregnancies per 100 women-years (Halpern et al., 2010, Raymond et al., 2011). This correlates to a 2.4\% pregnancy risk in 6 months which is much lower than the pregnancy risks for male condoms (7.8\%), female condoms (11.1\%) and the use of spermicides (15.7\%) (Taylor, 2009, as cited in Halpern et al., 2010). Despite being an effective method of pregnancy protection, one of the main concerns was the evidence of side effects in the trials. Between $18 \%$ and $89 \%$ of women experienced irregular 
bleeding or spotting when taking levonorgestrel (Raymond et al., 2011). Another side effect was menstrual cycle irregularity in which the cycle was either shortened or extended past what was normally expected (Raymond et al., 2011). Other side effects experienced by participants were dizziness, nausea, and abdominal pain, although these were uncommon (Chang-hai et al., 1991). A post-coital oral contraceptive intended for use after each act of sexual intercourse and consisting of levonorgestrel was available as Postinor in Eastern Europe and Asia throughout the 1980s to mid-1990s. This product marked the first packaging of a peri-coital contraceptive method. Postinor consisted of a pack of 4-10 tablets, each containing $0.75 \mathrm{mg}$ of levonorgestrel (Raymond et al., 2011). However, due to early studies' evidence of side effects such as irregular bleeding, spotting, and menstrual cycle irregularities, this method lacked support from the healthcare community, including organizations such as the WHO (Raymond et al., 2011). It is interesting to note that while evidence did demonstrate potential spotting, this side effect is not exclusive to the levonorgestrel peri-coital method. Studies of new low-estrogen combination daily OCPs have demonstrated as many as $25 \%$ of women experience spotting in the first cycle and $8 \%$ in later cycles (Kaunitz, 2004). Considering that the Postinor trials were not for extended periods of time, it is possible that over time the spotting would have decreased as typically occurs with daily OCP use. Although nearly $70 \%$ of participants of one study experienced menstrual disturbances, $66 \%$ said they were in favour of using levonorgestrel as a regular contraceptive (WHO Task Force, 2000). In 1996, Postinor was re-released as an LNG-EC product consisting of two pills each containing $0.75 \mathrm{mg}$ of levonorgestrel (Raymond et al., 2011).

Prior to the re-release of Postinor, there was no product specifically for post-coital use. In the 1960s, researchers conducted multiple trials of high-level doses of estrogen as a post-coital 
method of pregnancy prevention (Halpern et al., 2010). Estrogen has been associated with significant side effects and thus this method did not gain momentum. In 1972, a Canadian physician named Dr. Albert Yuzpe described the combination method of estrogen and progestin that can be taken up to 72 hours after sexual intercourse in order to prevent pregnancy (Wynn \& Foster, 2012). Known as the Yuzpe regimen, this method was favoured by reproductive health researchers as it avoided the side effects associated with high estrogen use (Wynn \& Foster, 2012). Throughout the 1980s the Yuzpe regimen continued to be the method of choice as it was cheaper than the few EC products that were available in some countries (Wynn \& Foster, 2012). In the 1990s, the WHO conducted trials comparing the Yuzpe regimen to a progestin-only postcoital method of contraception and found the progestin-only method to be more effective. This trial renewed efforts for a post-coital method and so although Postinor was unsuccessful as a peri-coital method of contraception, it was welcomed as a method of post-coital contraception.

The continuation rate of daily OCP has been shown to be as low as $29 \%$ after six months of use (Sundstrom, 2012). In fact, a large number of women stop and start a method of contraception depending on when they are at risk of pregnancy or switch method of protection depending on their individual needs (Frost et al., 2007). This is true for women who are participating in infrequent sexual intercourse, particularly younger women (Sundstrom, 2011). Many college students have a fear of forgetting to take OCPs since schedule changes make it difficult to remember to take it them the same time every day (Sundstrom, 2011). If a pill is missed, they are likely to feel uneasy at the idea of a possible pregnancy (Sundstrom, 2011). Infrequent sexual intercourse is correlated with a higher rate of non-use of contraceptives and a much lower rate of continuous use. Non-use increases in women who are not in a relationship or 
who have sex only once a month, in comparison to those who are sexually active 2-3 times a week (Frost et al., 2007).

For women who are having infrequent sexual intercourse, it is clear that there is a desire for a contraceptive method that can easily be taken when sex occurs or is expected to occur. Although Postinor as a peri-coital contraceptive method was unsuccessful, small subsets of women globally are choosing to use LNG-EC as a preferred method of pregnancy prevention (Keesbury et al., 2011; Lerkiabundit \& Reanmongkol, 2000; Opuku \& Kwaununu, 2011). Women are willing to pay more for LNG-EC than the daily OCP because LNG-EC provides them with more control and more choice (Coeytaux, Wells, \& Westley, 2009). This is especially true in a number of countries where women are opting to use LNG-EC as their primary method of contraception rather than use OCPs or other available methods. A study in Ghana interviewed 467 women of reproductive age in which $56 \%$ were buying LNG-EC prior to having sexual intercourse (Opuku \& Kwaununu, 2011). More than half (61\%) had used LNG-EC between 2-5 times, while $18 \%$ had used it more than six times as a method of contraception. Only $21 \%$ of the women interviewed had used LNG-EC once in their lives. Less than half of all the women revealed that they would not use daily contraception, instead choosing to maintain the habit of taking LNG-EC after sexual intercourse. A similar study in Kenya revealed that of 147 women ages 20-29, 58\% were "repeat" users of LNG-EC (Keesbury et al., 2011). This was defined as having used LNG-EC at least twice in the past month. Almost half of the women had used LNGEC "every time" or "most times" they had had sexual intercourse in the last month (Keesbury et al., 2011). This was because $57 \%$ of the interviewees engaged in infrequent or irregular sex and preferred LNG-EC as a mode of protection since it was more convenient than any other method. (Keesbury et al., 2011). Similarly in a study in Thailand, 39\% of women had used LNG-EC four 
times in the past month due to its convenience for women who were only having occasional sexual intercourse (Lerkiabundit \& Reanmongkol, 2000). In fact, only 3\% of the women interviewed used LNG-EC for a situation such as the condom breaking or other method failure.

Although studies have shown side effects were present with levonorgestrel which may deter some women from using peri-coital contraception, other studies have shown that it is possible to maintain the effectiveness of levonorgestrel with a smaller $0.75 \mathrm{mg}$ dose. As well, the peri-coital contraceptive pills will not contain any estrogen which generally causes the side effects experienced by women who use combined hormonal products (Raymond et al., 2011). This may provide women with the same efficacy in pregnancy protection while cutting down on such side effects as spotting and menstruation irregularities. The nature of a lower-dose pericoital contraceptive method as an available option if, and when, penile-vaginal intercourse occurs makes it a potentially advantageous method of contraception for some women. A variety of methods also provides women with more choices in pregnancy prevention options. With the supporting evidence that small subsets of women are already using post-coital contraception as a sex-dependent method of contraception, reintroduction of the peri-coital contraceptive pill could be a valuable addition to women's contraceptive options. 


\section{Chapter 3: Theoretical Framework}

This chapter is divided into three sections; in the first, I provide some history pertaining to the contraceptive movement in Canada. I then connect this history to the theory of reproductive justice and situate my research within this framework. Finally I explore social constructionism and the influence of discourses, their relation to reproductive justice, and their importance as the foundations of my project.

\section{A Brief History of Contraception in Canada}

In 1892, the Canadian Criminal Code prevented any advertising related to contraceptive or abortive practices (Bouma \& Bouma, 1975; Swinton, 1975). Despite this legislation, Canadian women still found access to barrier methods such as Lysol douches and Quinine pessaries (McLaren \& McLaren, 1997). In addition, there was a significant decline in fertility rates in Canada between 1880 and 1920 (Mackenzie, 1972; McLaren \& McLaren, 1997). However, there was much dissatisfaction with the available methods and many women still experienced unintended pregnancies and were unable to practice birth spacing.

By the early 1930s, there was evidence of family planning movements in other countries, primarily the UK movement led by Mary Stopes and the US movement led by Margaret Sanger. Despite these movements in the US and UK, there was no clear indication of such a movement in Canada. Canadian women wrote to Stopes and Sanger in hopes of bringing the movement to Canada. They also detailed their personal circumstances, such as this woman from Oshawa, Ontario who wrote, "I am 37 years of age and I feel that I have had enough children, indeed I think it is a bigger sin to bring children into the world when you haven't enough to keep them than it is to try to prevent them" (as quoted in McLaren \& McLaren, 1997, p. 25). Other women 
echoed the same sentiments of distress about having too many children and not enough resources, especially given the situation of living in the aftermath of the 1929 Depression.

In fact, a family planning movement did exist in Canada and had been growing quietly for some time. In 1923, feminist activists created the Canadian Birth Control League after Margaret Sanger held a public lecture in Vancouver, BC (McLaren \& McLaren, 1997). In comparison to other countries, the contraceptive movement in Canada had a slow start as it did not immediately have a distinguishable leader. The Canadian movement was not even fully established until the mid-1930s by which time the contraceptive movements in the US and the UK had garnered much attention. The establishment of the Canadian contraceptive movement coincided with the creation of the Parents' Information Bureau, an organization that focused on disseminating contraceptive information to married couples and families (McLaren \& McLaren, 1997). This organization was created by Alvin R. Kaufman who owned a rubber manufacturing plant and had become interested in contraception when he noticed the high levels of poverty his employees experienced (Swinton, 1975; McLaren \& McLaren, 1997).The first contraceptive clinic opened in Hamilton, Ontario in 1932. By the late 1930s, Kaufman had opened contraceptive clinics throughout Southern Ontario. These successful launches led to the opening of many more clinics throughout the province. In 1934, the Family Planning Association of Winnipeg was established and provided home visits to approximately 150 new patients each year (Swinton, 1975). The staff was entirely comprised of volunteers.

In 1936, authorities arrested Dorothea Palmer, a nurse who worked at one of Kaufman's clinics, for distributing informative pamphlets about contraception near present-day Ottawa, Ontario (Dodd, 1983; McLaren \& McLaren, 1997). Her trial included testimony from members of the Catholic Church, physicians, and most notably, 21 women who had used the services 
provided by these clinics and argued their importance and value (Dodd, 1983). In 1937, the court dropped the charges against Palmer (Dodd, 1983). This was a significant moment in the history of the Canadian family planning movement. However, contraception provision was not legalized until 1969, the same year abortion restrictions were eased (Bouma \& Bouma, 1975; McLaren \& McLaren, 1997).

Kaufman became interested in contraception after seeing the poverty his employees experienced; they had so many children and very few resources. This was an argument used by many in the Canadian contraceptive movement: contraception would be a particularly valuable addition in Canada as a way to control the fertility of the poor. In fact, most arguments for contraceptive movements in general stemmed from economic, and perhaps more frightening, eugenic principles. Eugenics was a term created by Francis Galton to describe the desire for "good breeding" in society and consisted of practices to maintain racial purity, particularly to protect the white race (Grekul, 2008). While many feared the introduction of contraception would result in a decline of offspring from those who were deemed "fit" (i.e. the wealthy white population) to parent, contraception was also appealing in that it would function to prevent the "unfit" from reproducing. Margaret Sanger supported this sentiment and wrote, "more children from the fit, less from the unfit - that is the chief issue of birth control" (as quoted in Ratcliff, 2002, p.193). Thus many marginalized communities in North America, particularly poor women, racial and ethnic minorities, and the mentally disabled, were coerced into contraceptive practices such as forced sterilization.

After the Second World War and the horrific events of the Holocaust, the justification for the contraceptive movement shifted away from eugenics towards neo-eugenic and Malthusian or neo-Malthusian trains of thought. The neo-eugenic theory for the contraceptive movement 
focused on welfare, the burden of minority groups on tax-payers' money, and a fear of overpopulation (Kluchin, 2009). Malthusian thought included fears of overpopulation but also focused on the well-being of individual families and how fertility control could ensure health and happiness (Kluchin, 2009; McLaren \& McLaren, 1997). Yet there continued to be an emphasis on who should be prevented from procreating. Neo-Malthusians believed that the lower classes were to blame for overpopulation but noted that these classes only existed because of the increased population size (Kluchin, 2009; Rainwater, 1967). Thus the need for contraception was important to not only increase the well-being of individual families but to improve general standards of living for all. This emphasis on class and poverty can be found in Canadian family planning literature up until the end of the 1970s. In a compilation funded by the Department of National Health and Welfare published in 1975, family planning experts in Canada thoroughly examined the state of contraceptive service delivery. In a chapter discussing family planning in rural areas, a number of physicians were invited to write in with their experiences and opinions on the topic. As Dr. Jackson from Milden, Saskatchewan wrote:

Family planning is adequate and really quite well organized among educated and high income groups in Canada. Nevertheless there is great need to supply counselling for the chronic unemployed, delinquent alcoholic and other underprivileged people who seem unreasonably anxious to share their misfortunes with numerous offspring. (As quoted in Mackenzie, 1975a, p. 21)

These so-called "underprivileged people" are addressed again in a later chapter in which an author debunks some popular myths about contraception in Canada. The third myth the author addresses is the belief that poverty will be reduced if family planning services are available to the poor. In response to this myth the author writes:

Conversely, the ill-defined poor do, usually, have a physician...The establishment of public clinics geographically near to them does not markedly improve their performance. This group is hard to reach... They are housebound in the urban society, chained to their 
dwellings by children, a lack of resources, few or no friends capable of helping; an attitude of quiet hopelessness is the result. (Mackenzie, 1975b, p. 31)

And so what does the author propose is the solution to improve family planning practices for lower income individuals in rural settings?

In this group of house-bound impoverished, demoralized persons, family planning has already passed them by. They have families. These families were rarely planned but represent the results of earlier crises. What they now seek is family limitation or termination. The solution lies in sterilization and many would welcome this. In this group, female sterilization is the best solution...(Mackenzie, 1975b, p.31)

So despite decades passing and an apparent acknowledgement that eugenics was no longer an appropriate justification for the availability and use of contraception in Canada, evidently there were still some problematic ideas about how to address issues of poverty in the country.

However, this focus on population growth caused an increase of family planning organizations in Canada. Between 1950 and 1970, the family planning movement in Canada made further progress. In 1955, Gilles and Rita Breault established SERENA, a movement that focused on natural family planning methods (Swinton, 1975). Family planning activists George and Barbara Cadbury formed the Planned Parenthood Association of Toronto in 1961 and in 1963, British Columbia granted a provincial charter to the Society for Population Planning, acknowledging the Association's right to provide services (Swinton, 1975). Family planning activists in Canada also formed organizations throughout Alberta, Quebec, and Ontario. By the late 1960s, provinces across Canada were encouraging the establishment of family planning services and provincial associations joined with some religious institutions to create the Family Planning Federation of Canada (Ball, 1975). In 1975 it was renamed the Planned Parenthood Federation of Canada. Clinicians and researchers in Canada made tremendous efforts to expand family planning services across the country. The First National Conference on Family Planning 
took place in February 1972 in Ottawa, Ontario and recommended that more family planning materials be made available (Schlesinger, 1975). Thus the compilation created in 1975 with funding from the National Department of Health and Welfare was a call to action to encourage the provision of family planning services across Canada to eliminate poverty but also to provide the public with more agency to practice birth spacing and pregnancy prevention.

During these years, there was also movement-building among women across the country. Women organized groups in Vancouver, Halifax and Quebec and so began the second-wave feminist movement in Canada. In the 1960s women formed groups such as the Canadian Committee on Status of Women and la féderation des femmes du Québec (Robbins, Luxton, Eichler, \& Descarries, 2008). Feminist organizations at this time engaged in a range of issues in Canada including marriage equality, labour and wage equality, inclusion of women in the Arts, sexual expression, and especially, access to contraception and abortion (Backhouse, 1992). Women activists in Toronto created the Voice of Women in 1960 in response to the possibility of a nuclear war (Vickers, 1992). This organization had an active voice in the fight for family planning throughout the 1960 s and joined other groups to rally for the legalization of contraception (Vickers, 1992). This feminist activism throughout the 1960s and 1970s was monumental in increasing women's rights in Canada. However, the second wave feminist movement in Canada failed to include women of colour and did not focus efforts on the issues that most impacted marginalized women. There was rarely representation of Indigenous women or other racialized women in the movement despite the existence of a number of organized groups of these women that were also working towards the same goals (Robbins, et al., 2008). 


\section{Reproductive Justice}

The example of Canada's focus on eliminating poverty as a justification for the contraceptive movement demonstrates "stratified reproduction", a term coined by Shellee Colen and used to describe, "the power relations by which some categories of people are empowered to nurture and reproduce, while others are disempowered" (as quoted in Ginsburg \& Rapp, 1995, p. 3). Across North America, white, upper-class women historically have been encouraged to reproduce and fulfill the role of motherhood while low-income racialized women were accused of excessive "breeding” and mis-using state resources (Ginsburg \& Rapp, 1995). Many contraceptive options have once been represented as ways to curb this "breeding" and exhaustion of resources. This access to contraception as "population control" did not afford marginalized women choice or agency.

In the United States and Canada, marginalized women launched the reproductive justice movement when they began to mobilize to fight for many reproductive rights including equal access to a variety of affordable contraceptives and safe, legal abortion. Reproductive justice challenged second wave feminism and called to expand the contraceptive movement to include the needs of the marginalized. Although US activists first created the concept of reproductive justice in the 1990s, the term "reproductive justice" was first coined at a 2003 SisterSong conference led by Loretta Ross and other advocates who were interested in bridging the gap between reproductive rights and social justice for women of colour and other minority groups (Ross, 2006; Ross \& Roberts, 2006). The concept of reproductive justice stems from the theory of intersectionality which considers that race, gender, class, and ability are connected and interlocked to shape an individual's experiences (Hesse-Biber \& Yaiser, 2004). Reproductive 
justice is then defined as "the complete physical, mental, spiritual, political, social, and economic well-being of women and girls, based on the full achievement and protection of women's human rights"(Ross \& Roberts, 2006, p.14). Reproductive justice consists of the equal right to: a) have children b) not have children and c) parent children (Ross \& Roberts, 2006). Issues of sexual and reproductive health are more complicated than a woman's individual choice or access and depend on social, political, and economic factors that influence an entire community's wellbeing (Ross \& Roberts, 2006). The movement expanded the focus of reproductive oppression to be more inclusive of all inequalities and how they influence individual and collective well-being. Reproductive justice frameworks have been adopted by Canadian activists such as Jessica Yee, who has done extensive work on contraceptive use in Indigenous populations.

Access to a variety of contraceptive methods is an issue of reproductive justice. Thus, situated within a reproductive justice framework, the peri-coital contraceptive pill is a potentially valuable addition to the existing variety of available contraceptive methods. Some women may feel there are plenty of current contraceptive methods to suit their particular needs. They may decide that the peri-coital contraceptive pill is not the right choice for them and choose other methods or practices. However, for other women the emergence of a female-controlled, usedependent method of contraception is a valuable addition to the existing method mix. A new contraceptive option such as the peri-coital contraceptive pill is certainly beneficial as not only does it increase the number of available contraceptive methods, thus increasing a woman's choice and agency in reproductive health decisions, but it can also potentially bridge a gap in current methods to help prevent unintended pregnancy. 


\section{Social Constructionism}

Social constructionism posits that understandings of the world are constructed through social interactions (Burr, 2003). As a theory, social constructionism emphasizes a social focus of the world over an individual focus. Society creates what we understand about the world around us. Thus, society simply constructs and maintains concepts like "knowledge" and "truth" in dayto-day practices. Interactions between individuals creates knowledge through the use of one of the most important aspects of social constructionism: language. Language provides a tool to structure the meaning of an object and share it with others (Burr, 2003).

Language also makes abstract thoughts and concepts possible. According to sociologist Peter Berger, who wrote The Social Construction of Reality in 1966, language "allows me to objectify a great variety of experiences coming my way in the course of my life. It typifies experiences allowing broad categorization to share meaning with others" (p. 39). Language is used as a tool to mediate an objective reality of society which is then internalised by the individuals within it. Therefore, conversation is the most important means of maintaining, modifying and reconstructing reality (Andrews, 2012). Language is responsible for creating "facts" and "truths" about our world. As a society, we have shared meanings and understandings so concepts do not have to be redefined over time. Berger wrote, "language is capable of becoming the objective repository of vast accumulations of meaning and experience, which it can then preserve in time and transmit to following generations" $(1966, \mathrm{p} .37)$. This suggests that many concepts are defined at a point in time and then largely taken for granted as time progresses.

Berger again writes, "to be in society is to participate in its dialectic" (1966, p.129). Thus it is difficult to exist in society without using the language that is made available to us. While it 
may be valuable to have pre-defined concepts to aid in communicating our realities to others in society, this statement relies heavily on an assumption that all pre-defined concepts are clearly defined. Within social constructionism, discourse is defined as a collection of texts (written and oral) pertaining to a particular subject (Hall, 1997). A discourse is the dominant way to talk about a topic and thus becomes the primary way to share our experiences. This is no doubt problematic as our understandings of the world change but the language we use does not. As well, discourses pose a dilemma if our experiences do not fit into them and we do not have a way to talk about them.

According to renowned theorist Michel Foucault, discourses encompass not only what is being said but who is saying it, how s/he have said it, and the context in which it was said (Foucault, 1978). Discourse is inherently related to power and knowledge and therefore, particular statements about a subject can help individuals understand or create knowledge about it (Hall, 1997). Knowledge is always related to power because it is applied to the regulation of social conduct in practice (Hall, 1997). It is important to emphasize that whoever determines the discourse is also determining what can be understood or known about the topic. Therefore, language and knowledge are politicized and can have serious implications for practice. For these reasons, Foucault cautioned to be critical of discourse. While language and discourse are socially constructed, the effects of their use are very real.

Indeed, evidence of the implications exist in both the historically gendered nature of medical terminology, which can be analyzed from a critical feminist perspective, and the problematic representations of contraception that emerged regarding low-class individuals in Canada. Terminology is often gendered in a way that discriminates against women. Emily Martin explored differences in adjectives and terms used when comparing the female egg and the 
male sperm and found many gendered discrepancies. According to Martin, literature describes sperm as active, aggressive, and powerful while the egg remains docile, passive, and immobile (1991). These associations speak volumes to how men and women are represented and valued within society. A decade later, another study provided further insight into the gender bias in healthcare terminology, particularly surrounding fertility in couples. It appears that when fertilization is successful, it is because the sperm has been successful in its purpose. Yet when fertilization is unsuccessful or when a couple is declared "infertile", it is due to the failure of the egg to fertilize (Bowker, 2001). Upon careful examination of a number of databases, it appears that there are a number of these terminology discrepancies between discussing similar issues in men and women. For example, infertility caused by auto-antibodies is referred to as "autoimmunity" in men. When the same autoimmunity occurs in women it is most often referred to as "cervical hostility" or "hostile" mucous (Bowker, 2001). The use of hostility evokes a negative connotation that is not associated with the term "autoimmunity". These examples demonstrate the gendered language within reproductive health, which scrutinize the female body and revere the male body, and therefore may disempower a woman in her sexuality and health.

Critical discourse analysis was developed to explore how language and grammar creates meaning, how they influence individuals to think in certain ways, and how they can even covertly manipulate individuals by emphasizing Foucault's notion of the importance of power in discourse (Hall, 1997). Feminist critical discourse analysis, stemming from critical discourse analysis, can be used to examine the problematic nature of both gendered terminology and racialized discourses that exist in reproductive health conversations as it examines discourses that maintain "hierarchically gendered social orders" (Lazar, 2007). Discourses often express patriarchal views which privilege men over women and this is evident in the way gendered 
language associates femininity with negative terms and masculinity with far more positive ones as demonstrated by the examples above. This creation of a binary of terminology leads to a discursive subordination of women that has very real implications. To associate aspects of the female body with negative terminology can no doubt influence a physician's view of the female body in practice. This in turn can influence how a physician discusses a woman's body and how the woman may then view herself. The interactions between gender and power in discourse are often complex (Lazar, 2007). There are overt forms of sexism that exist in text but it is also important to acknowledge more subtle forms that may exist (Lazar, 2007).

Patricia Hill Collins' (1990) idea of a "matrix of domination" considers that gender, race, class, and ability are social constructions and are connected and interlocked in an individual's experience (as cited in Hesse-Biber \& Yaiser, 2004). Intersectionality then recognizes the complexity of a woman's life and socially locates her within it (Weber, as cited in Berger \& Guidroz, 2009). While I am not conducting a critical discourse analysis, I will be drawing on this framework when exploring the implicit themes that arise surrounding the language women use to talk about contraception. I certainly aim to examine how multiple women's experiences influence the discourses they use and if different experiences have the power to influence language in different ways.

Power comes from a variety of sources and structures within society. By inquiring into the way language may change when talking about contraception to physicians, friends, social media, and popular culture, I aim to explore where particular sources of power are pertaining to contraception and how these powers influence the dominant discourses that emerge within our discussions. Foucault also maintained that in the creation of one or multiple authoritative discourses, multiple silences are also formed (1978). He argued that discourses pertaining to sex 
are not silences but rather, a number of forces come together to establish a pervasive discourse about sex (Foucault, 1978). Individual's experiences of sex then either fit into this hegemonic creation of what is an acceptable discourse surrounding sex, or it does not and becomes silenced (Foucault, 1978). However, if there is space for the silences to be explored, there is potential for competing discourses to emerge. Allowing women the space to share their experiences that have been silenced by the dominant discourses may result in evidence of shared experiences which could be considered a competing discourse to what is known about contraceptive use. An examination of language and terminologies reflects the use of a socio-cultural paradigm to explore frameworks for new contraceptive methods. Rather than focusing on the scientific facts, this paradigm concentrates attention on the attitudes, relationships, roles, and interactions with culture (Dickson, 2008). The peri-coital contraceptive method may be efficient and intuitive, but without the proper language and terms with which to discuss it, it may not be a successful method. 


\section{Chapter 4: Methodological Framework}

In this chapter I explain why I chose focus group discussions (FGDs) as the data collection method for this project. As well, I detail my methods, the research process, and the analytic framework.

\section{Methodology}

My thesis is strongly influenced by feminist research practices as historically, research in medicine focused on the male subject with studies conducted by male researchers. Many decisions, even pertaining to women's health, have been made by men in the field of sexual and reproductive health. Feminist research is produced for women rather than on women (de Oliveira, 2011). This project extends further to produce research with women, a concept that is associated with participatory action research. This thesis highlights the significance of the woman's voice in decisions of reproductive health options and the necessity of choice in providing options to prevent pregnancy. It is important to make women's experiences with contraception visible and show possible contradictions and challenges to mainstream medical research (Brooks \& Hesse-Biber, 2007). I conducted my thesis using qualitative methods, specifically focus group discussions, and drew from a feminist action-oriented participatory research praxis.

\section{Participatory Action Research}

Participatory action research (PAR) is defined as research in which the participants and researchers work together to explore a problem and offer solutions (Wadsworth, 1998). PAR consists of "a collaborative process of research, education, and action" (Hall, 1981 as cited in 
Kindon, Pain \& Kesby, 2007, p.9). There is an emphasis within PAR to connect with politics and social change to re-politicize participation and empower individuals within the research (FalsBorvla 2006; Kapoor, 2005). Researchers popularized participatory action research post-second world war and referred to it simply as "action research". PAR became particularly popular when it was brought into mainstream practice by Paulo Freire in the 1970s. Freire described himself as an "emancipatory educator" for poor and marginalized groups and had a key role in the critical pedagogy movement (Wadsworth, 1998).

Presently, a branch in the practice known as feminist participatory action research exists. This practice acknowledges gender differences in participants and the potential gendering effects that can result from poor PAR practices. Ideally, feminist participatory action researchers are aware of their privileges and are interested in collaboration with real people and their experiences. These researchers are concerned with the importance of providing space to individuals in order to empower them. Participatory action research is context bound and addresses real life problems. FGDs are a common practice within PAR as they are ideal for providing space to talk about difficult topics and help balance the researcher and participant relationship. PAR emphasizes a plurality of knowledge and "those who have been most systematically excluded, oppressed, or denied carry specifically revealing wisdom about the history, structure, consequences and the fracture points in unjust social arrangements" (Fine, 2008 as cited in Kindon et al., 2007, p.9) Using a PAR approach to the research is particularly important as there have been, historically and presently, many assumptions of normality and homogeneity in aspects of sexual and reproductive health. However, while I draw on many aspects of feminist participatory action research, my thesis is not a true PAR project. Although I engaged with women through the data collection process and will share the findings of the study 
with them, there was no participation from women in the conceptualization or design of the study.

\section{Focus Group Discussions as Method}

Focus group discussions are often used in evaluation research, exploratory research, or multi-method research projects (Leavy, 2007). An examination of the language and frameworks of an emerging reproductive technology falls into the category of exploratory research, as I collected data on a subject where little is known (Leavy, 2007). This research focused on the attitudes, thoughts, feelings, and personal experiences of participants in a group setting in order to direct future research of the peri-coital contraceptive pill. Sue Wilkinson, who has written extensively about FGDs, explains that they demonstrate, "the co-construction of realities between people, the dynamic negotiation of meaning in context" (1998, p. 112). Exploring meaning in different contexts is important to this project as I opened up the discussion about contraception to women's experiences and opinions. Exploratory research also focuses on understanding culture and social norms. Social norms are society's understanding of behaviours that are mandatory, acceptable, or prohibited (Crawford \& Ostrom, 1995). FGDs are often used to understand social norms as the conversations that take place reveal normative behaviours or beliefs in the group (Hennink, 2014). The social moderation of participants' behaviours and beliefs by others in the FGD also highlights outlying beliefs or behaviours (Hennink, 2014).

Focus group discussions can also provide information about the informal language that is used by the group in conversation (Leavy, 2007). In fact, the process of a FGD has been referred to as "a happening", in which the group discussion is a narrative process that is "focused" or moderated by the researcher but in which participants use their own terms to discuss their ideas 
or emotions (Leavy, 2007). Kitzinger (1994) highlights the importance of FGDs as she states, "group work ensures that priority is given to the respondents' hierarchy of importance, their language and concepts, their frameworks for understanding the world...everyday forms of communication...may tell us as much, if not more about what people 'know"' (p. 173-174, as cited in Leavy, 2007 [her emphasis]). This statement reflects the emphasis on "natural" language within FGDs and how this language itself acts as data.

Other advantages of focus group discussions are that, because they are a more "natural" process using everyday modes of communication, they may decrease artificiality in data (Wilkinson, 1999). The researcher plays a smaller role in the production of information throughout the group session than in other forms of qualitative data collection. Anything and everything participants may say in a FGD can be considered pertinent data. FGDs also emphasize context which helps relate the dialogue of a discussion to women's personal experiences (Wilkinson, 1999). In fact, separating a FGD from context is difficult because of their social nature.

There are important considerations to make when using FGDs as a method for data collection. Specifically, in order to gather data from various individuals' experiences, it is necessary to consider the sampling process for the focus groups. Homogeneous sampling involves placing participants in groups with a shared characteristic, such as geographical location (Leavy, 2007). This can be helpful in opening up conversation as a shared trait can influence discussion and increase comfort levels among women. To understand experiences and opinions of contraception, it is necessary to collect information from various individuals across Canada. Therefore, the best approach for sampling is to organize FGDs so that each group has women of 
different backgrounds, but each group itself shares a common characteristic or trait to help facilitate sharing experiences.

Although women were not specifically asked to share their contraceptive experiences, some women shared them when they talked about the language they have used to communicate about different methods. Listening to individuals' stories and experiences is especially important in qualitative research and is often used in reproductive health research. Within a socio-cultural paradigm, research on a particular topic studies not only the issue at hand but includes the context of the individual's life history, culture, and social roles (Dickson, 2008). Focus group discussions have the ability to access the experiences of groups who have previously been silenced, which is particularly important when thinking about the problematic history of contraception in Canada (Leavy, 2007). FGDs create an environment that is essential for those silenced to share and compare experiences. Conversation includes sharing truths, whether collective or separate, and plural personal experiences in a non-judgmental space (Belenky, Clinchy, Goldberger \& Tarule, 2008). However, the "group effect" can occur in which discussion and debates among group members opens up the conversations and challenge assumptions or beliefs within the group (Leavy, 2007; Wilkinson, 1999). The "group effect" can be especially interesting in sexuality and gender studies because often issues are "naturalized" in a way that people may not recognize their subjectivity (Leavy, 2007). Opening up conversations to a group can challenge people's opinions and beliefs and create a space to encourage critical thinking. This environment can be positive, especially if women discuss experiences of sexual and reproductive health which contain misinformation and varying personal anecdotes. However, the "group effect" can be problematic if some participants are silenced or feel uncomfortable sharing their stories and opinions (Leavy, 2007). Thus, it remains important for the researcher to 
create and maintain a safe space for participants to vocalize their feelings. For those who are interested in the subject but are soft-spoken or would rather listen to the conversation than actively participate, I provided a short exit survey in which they could record their ideas as their input is still valuable to my research.

Joan W. Scott has written extensively on experiences and their value to our understanding of a topic. She notes that experience is complicated to define but is always challenged and therefore political (1991). This may be especially true in topics such as contraception, abortion, and other reproductive health services which have been highly politicized. The need for individuals to voice personal experiences and challenges in reproductive choice and pregnancy prevention is important to personalize the issue and remind politicians and policy makers that the laws and policies surrounding contraception have very real consequences to individuals worldwide.

\section{Methods}

\section{Study Design}

I based this study on the pilot study I conducted as my undergraduate honours thesis project in the Faculty of Health Sciences at the University of Ottawa. In the earlier project, I conducted five FGDs with English-speaking undergraduate University of Ottawa students and my colleague conducted three FGDs in French. The study explored how university students would talk about peri-coital contraception in both of Canada's official languages. A total of 31 students participated and this pilot project helped me familiarize myself with the study design and make any necessary modifications prior to launching a larger and more geographically diverse study. 
For my thesis project, I conducted seven FGDs with women across Canada between August 2014 and April 2015. One FGD took place in each of the following locations:

Charlottetown, Prince Edward Island; Halifax, Nova Scotia; Edmonton, Alberta; Vancouver, British Columbia; Ottawa, Ontario; Toronto, Ontario, and Thunder Bay, Ontario. These locations were purposively selected to reflect the geographic diversity both within Canada (i.e. Eastern, Western, and Northern Canada) and within Canada's most populous province (urban vs. rural Ontario). The five provinces also reflect different policy environments with respect to contraception with variations in prevalence rates and methods used.

\section{Selection of Participants}

I recruited participants primarily by posting online Kijiji advertisements and other online community bulletin boards. I also reached out to university campuses, community organizations, community health centres, Canadian reproductive health researchers, sexual health centres, and other groups that were sex-positive or women-centred. Many organizations posted physical flyers and advertised information about the study through Facebook, Twitter, or other social media.

Participants were eligible to participate if they 1) self-identified as a woman $\left.{ }^{2}, 2\right)$ were between 18-45 years of age (inclusive), and 3) were sufficiently fluent in English to participate in the FGD. I originally attempted to separate groups into relationship status but when recruitment began I found that many women did not feel they fit clearly into one category of single/casually

\footnotetext{
${ }^{2}$ I would like to acknowledge that despite the use of cis- and trans- to identify individuals within feminist academia, I used the non-academic term "woman" to ensure the eligibility criteria was clearly understood by potential participants. This is not to say that trans-individuals were not welcome to participate but they had to self-identify as a woman in order to do so.
} 
dating or long-term relationship of more than one year. Thus, I removed the category from the criteria when it became clear it was difficult to organize the groups in that way.

If potential participants were interested in the study, I sent them each a consent form by email and I asked them some questions, either by email or phone, to ensure they were eligible to participate. I then used the online resource Doodle to create online surveys that participants could anonymously fill out. These surveys offered a variety of possible dates and times to meet for the discussion and I sent them out well in advance of the date so that women could accommodate the times and I could book the necessary travel plans. I picked the date and time that was chosen by the most women in each city and then sent out an email detailing the information about the discussion and a reminder email closer to the date.

\section{Focus Group Discussion Process}

At the beginning of each FGD, I reviewed the consent form orally with the participants to ensure that the study's objectives were clear and that participation was completely voluntary; any participant could leave the FGD at any point in time without penalty. I explained to participants they were welcome to use a pseudonym during the FGD rather than reveal their real name, but because of the nature of the study, I could not ensure complete confidentiality. I held all but one FGD in small conference rooms on University campuses. The universities donated all rooms except for the room at the University of Alberta, which required a small booking fee. University campus' women centres recommended and booked most of the rooms. I conducted the Toronto FGD at a community centre in the downtown core. The discussions lasted anywhere from 75-120 minutes with some extra time at the end for participants to complete the brief anonymous exit survey. 
Each FGD began with a brief introduction by each participant and then a broad discussion of contraceptive knowledge and where this knowledge was attained. I then introduced a discussion of the terms "oral contraceptive pill"3, "emergency contraception", and "mifepristone" to see if participants were familiar with each method and if so, how they talked about them in different scenarios with friends, physicians, sexual partners or in social media. I then directed the discussion to "peri-coital contraception" and what this term meant to them. I also asked how they would talk about peri-coital contraception in the same scenarios as the other contraceptives. Participants discussed how to avoid confusion of contraceptive terms and ways in which to create clear and concise language with which to talk about peri-coital contraception. They discussed the framing of the peri-coital contraceptive and who would use this method and what is important to know about it, as well as any concerns or questions they had about the method. Finally, I asked women about sexual and reproductive health issues that were specific to their geographical location.

I gave each participant a $\$ 5$ gift card for Starbucks to thank them for their participation. The participants received the gift cards at the beginning of the FGD so they could keep them even if they decided to leave the FGD early. With the permission of the participants, I audiorecorded and transcribed the FGDs. I also made short memos while traveling which documented the context and dynamics of each FGD as well as any themes that were prominent within the discussion. I provided participants with a card at the end of the FGD in which they could provide contact information so the key findings can be sent to them. As well, I encouraged them to contact me with any questions or information they wanted to share regarding contraception. I stored all data and forms from the study in a safe and secure location on the University of Ottawa campus to maintain confidentiality.

\footnotetext{
${ }^{3}$ Definitions of each term can be found Chapter 1 of this thesis.
} 


\section{Analytic Approach}

After I conducted each FGD, I transcribed it in a secure location. Using these transcripts, as well as my notes and memos, I conducted a content and thematic analysis using ATLAS.ti software to organize the data. Prior to analysis and informed by the pilot study, I created a codebook of a priori codes based on answers and topics I expected to come up in the FGD. The pilot FGDs I conducted for my honours thesis informed the development of these predetermined codes. I used this codebook to analyze each FGD and as new codes emerged from the data set, I returned to the other FGDs and re-coded for these inductive codes. I then examined overarching themes from the FGDs as well as specific themes that may be related to geographical location or age.

Beyond the completion of this monograph, I plan to submit two manuscripts detailing the results of the study for submission to academic journals. I also intend to send the participants the key findings of the study in a format that is more accessible to the community than an academic journal article.

\section{Ethics}

This study received ethics approval from the Health Sciences and Sciences Research Ethics Board at the University of Ottawa (File \# H06-14-11). The letter of approval from the University of Ottawa's REB can be found in Appendix A. 


\section{Chapter 5: Results}

This chapter presents the findings of focus group discussions to answer the research questions of this thesis. I have divided the chapter into subsections based on the FGD discussion guide. First I present the basic demographic information from the focus group discussion exit surveys. The subsections of background knowledge of contraception, oral contraceptive pills, emergency contraception, and mifepristone, address the research question: how do women talk about different available contraceptive and abortion technologies The subsection, peri-coital contraception, answers the research questions: How do these discourses influence the language and frameworks women use talk about the peri-coital contraceptive pill? And what are Canadian women's perceptions of and concerns about this potential contraceptive method? Finally the final subsection reveals over-arching themes found throughout the FGDs: contraception and stigma, contraception and men, misperceptions about contraception, and Canadian reproductive health issues.

\section{Basic Demographics}

A total of 38 women participated in the study and each FGD consisted of between three and seven participants. I present more information about the composition of the FGDs in Table 1. The exit survey at the end of each FGD collected basic demographic information about the participants. The average age of the participants was 29 years. Ten women cited their occupation as "student" while the rest reported a variety of occupations. The majority of women identified as White. Other ethnicities or races reported included Black $(\mathrm{n}=2)$ Asian $(\mathrm{n}=1)$ and First Nations or Aboriginal $(\mathrm{n}=2)$. Eight women identified as somewhat or strongly religious and their religious backgrounds included Catholic, Protestant or Other. Twenty-eight women said they 
were in a committed, monogamous relationship, 13 of whom were married. The majority of women identified as heterosexual although other sexual orientations included "queer" $(\mathrm{n}=1)$, "bisexual" ( $\mathrm{n}=7$ ), and "unsure" (n=2), and two women chose not to identify.

Table 1: Composition of FGDs

\begin{tabular}{|c|c|c|l|}
\hline FGD & Location & $\begin{array}{c}\text { Number of } \\
\text { participants }\end{array}$ & \multicolumn{1}{|c|}{ Description } \\
\hline 1 & $\begin{array}{c}\text { Charlottetown, } \\
\text { PE }\end{array}$ & 5 & $\begin{array}{l}\text { One single woman, four in committed monogamous } \\
\text { relationships; age 18-30. }\end{array}$ \\
\hline 2 & Halifax, NS & 6 & $\begin{array}{l}\text { One single woman, five in committed monogamous } \\
\text { or non-monogamous relationships; age 23-37. }\end{array}$ \\
\hline 3 & Edmonton, AB & 3 & $\begin{array}{l}\text { Two single women, one in a committed monogamous } \\
\text { relationship; age 19-37. }\end{array}$ \\
\hline 4 & $\begin{array}{c}\text { Vancouver, } \\
\text { BC }\end{array}$ & 7 & $\begin{array}{l}\text { Three single women, three in committed } \\
\text { monogamous or non-monogamous relationships; age } \\
\text { 31-42. }\end{array}$ \\
\hline 5 & Ottawa, ON & 4 & $\begin{array}{l}\text { All women in committed, monogamous } \\
\text { relationships; age 30-43. }\end{array}$ \\
\hline 6 & Toronto, ON & 6 & $\begin{array}{l}\text { All women in committed monogamous or non- } \\
\text { monogamous relationships; age 20-24. }\end{array}$ \\
\hline 7 & $\begin{array}{c}\text { Thunder Bay, } \\
\text { ON }\end{array}$ & 7 & $\begin{array}{l}\text { All women in committed monogamous relationships; } \\
\text { age 19-44 }\end{array}$ \\
\hline
\end{tabular}

\section{Background Knowledge of Contraception}

Women under the age of 29 primarily learned of contraceptive methods through personal online research of both scientific websites as well as lay information, such as blogs. When first seeking information about contraception, these women looked on the Internet prior to meeting with their physician to discuss methods in order to have a clear understanding of what method they desired. When asked if the Internet sources were medical websites and articles or personal blogs about women's experiences, a woman in Halifax named Jennifer replied,

I think equal parts both. Like I've definitely found the more official sources pretty useful for getting the basic knowledge of what is in different medications, like what are the sort 
of stats behind things? And then things more like blogs or message boards or whatever for getting people's actual experiences and sort of details about things like side effects that aren't stuff that you would find on those official sources that are just as relevant and useful.

Other women in the FGDs also found both clinical information and personal experiences to be valuable sources of information about contraception. For many women over the age of 29 , the Internet was not accessible to them when they were first seeking information. These women shared stories of going to their physicians and receiving daily OCPs without much conversation. A few women had conversations about contraception with mothers, sisters or female friends but it was not a common experience. Four women worked in healthcare and had jobs which exposed them to more information which broadened their knowledge of contraception. The majority of women agreed that their contraceptive education at school was inadequate at best, yet a few explained that they could not even comment because they had not received any at all.

\section{Oral Contraceptive Pills}

When asked what "oral contraceptive pill" meant to them, the majority of women responded with the terms "the pill" or "birth control". Other responses included "a pill that you take every day" or an association with "hormones". Some also suggested brand names of OCPs such as "Yaz" and "Alesse". All the women said that "oral contraceptive pill" was not a common term heard or used and they had only heard it used in clinical or medical circumstances. Women offered that the term was "too long", "too formal", or "too medical" to use and they much preferred to use "birth control" and "the pill", especially because these are such well-known terms. Natalie in Ottawa explained that the term "oral contraceptive pill" was "too long to say and everybody knows it by 'the pill' so why would I use more words than I have to?", while 
Amy added, "It [the term OCPs] seems that it's a very medical term for it and for a lot of women it's daily, right? It's a regular part of your life so you don't need to have the really medical definition for it anymore because that's just like, that's what you use." The terms, "the pill" and "birth control" were the most common in the contexts of conversations with physicians, friends, and sexual partners. When asked if they would talk about OCPs on social media platforms such as Facebook or Twitter, most women said that they might share a news story but they would never post anything personal in nature. Finally women discussed OCPs in popular culture and mentioned that if they were referred to in movies, TV or in magazines, the method would be called "birth control" or "the pill".

\section{Emergency Contraception}

When asked what "emergency contraception" meant to them, women responded with "Plan B" or "the morning after pill". Women who were older than 29 years of age cited "the morning after pill" as a more common term for this method whereas younger participants were more familiar with "Plan B". They speculated this was due to the fact that when LNG-EC first became popular it was only referred to as "the morning after pill" and "Plan B" was a term that was popularized in later years when the brand became available. Only one woman suggested an intrauterine device (IUD) could be used as a method of emergency contraception. Women disliked the term "emergency contraception" as it was "too long", "too formal", "too medical", and "too jargon-y". Some women disliked the use of "emergency" because it sounded far too urgent or dangerous to be used in the circumstances they were imagining. Michelle in Vancouver said, "I feel like you'd go with 'the morning after pill' rather than 'emergency contraception' 
because I think for a lot of people that evokes like, you made a mistake and now you have an emergency and you're not on the pill".

Women first began talking about stigma when the "emergency contraception" discussion was introduced. Women felt that individuals were judged by society for being irresponsible or participating in casual sexual encounters when seeking LNG-EC. Older women in Thunder Bay shared personal experiences of feeling shamed or stigmatized for seeking LNG-EC and having to "jump through all these hoops" in order to get it from their doctor, as at the time a prescription was still required. I was interested if this feeling was shared with the younger women in the group and they said that it really depended on the opinions of the pharmacist, whom they would likely be interacting with rather than their doctor. Participants explained that they still feel embarrassed or shamed when asking the pharmacist for LNG-EC and thought their friends felt the same way.

Similarly to OCPs, participants had only heard "emergency contraception" used in clinical or medical circumstances. Women explained that they rarely spoke to their doctor about LNG-EC but had more experience speaking with pharmacists. In that situation they said they would use "Plan B" or "the morning after pill". Some women said if they considered the situation to be more serious they may instead use "emergency contraception" to describe LNGEC. Women also explained they would use these colloquial terms when talking to friends and sexual partners, although some suggested they may not participate in a discussion about LNGEC if the sexual partner was new or casual. Women said they were less likely to post about LNG-EC on social media platforms than OCPs but they may post a news article. For those who would post a news article they said they would likely use "emergency contraception" as a way to educate their online peers and to keep the post from being considered personal. However, some 
women had seen LNG-EC referred to on social media by the more common terms "Plan B" and "the morning after pill". When asked about references to LNG-EC in popular culture, women echoed these terms.

In the discussions of LNG-EC, participants mentioned abortion quite a few times. There was some confusion that LNG-EC was somehow associated with abortion in terms of mechanism of action. This issue was usually clarified by another participant who was more familiar with the method. Far more often emergency contraception was associated with abortion in terms of shame and stigma that surround both methods. A few women also mentioned that they had seen articles online which referred to emergency contraception as abortion, but these were usually from anti-choice organizations. Jessica in Thunder Bay talked about the introduction of LNG-EC in Canada and mentioned that, "it was called the 'abortion pill' a lot back then wasn't it?". Other women in the discussions thought they had also heard the conflation of LNG-EC and abortion in media sources and their sex education a lot when it was introduced, but agreed that this conflation was still prevalent today.

\section{Mifepristone}

When asked what "mifepristone" was, the majority of women had no idea. Some women guessed that it was a kind of contraceptive method including a jelly, IUD, or patch. Only four women knew it was actually a pill used to induce an abortion. Once I explained the method and also suggested the term "medication abortion", some women said they had more commonly heard or used the terms "RU 486", "medical abortion", or "chemical abortion". Women were less surprised that they had never heard of mifepristone once they discovered that it was not currently available in Canada but were not very familiar with the method of medication abortion 
that is available (methotrexate and misoprostol). For those who had heard of the term, it was always in relation to access (or lack of) in Canada compared to other countries. Further, some had never even heard of a medication abortion at all and knew only of "surgical" methods. These women explained they would probably just talk about abortion broadly and then specify that there are different methods that can be used.

During the FGDs, the overall tone of the discussion of mifepristone and medication abortion was different than the discussions of other methods. Women were far less enthusiastic to offer opinions or responses to the questions I asked. However, some did say that they would talk to their physicians, friends, or sexual partners about these reproductive health technologies. The terms they would use in these situations included "medical abortion", "abortion pill", or again, just broadly talking about abortion. Women would only talk about mifepristone or medication abortion on social media platforms if posting a news article or political piece about mifepristone's status in Canada. Some were unsure if they would use the term "abortion" because of its politically charged nature and instead would maybe just talk about the prochoice/anti-choice debate. Women had not commonly heard abortion medications referenced in popular culture, although some women said they had heard or seen general references to abortion. Michelle from Vancouver explained that "people don't like to talk about abortion, period." Others agreed and explained that they rarely see it in popular media and that it was also never discussed by their physicians.

\section{Peri-Coital Contraception}




\section{Naming the Peri-Coital Contraceptive Pill}

No one had heard of the "peri-coital contraceptive pill" and very few deduced that it would be something used "around" sex as the prefix "peri" suggests. For those who hazarded a guess, the most common response was "a male pill". Once I explained what the peri-coital contraceptive pill was, all but one woman agreed that it would be a valuable addition to current contraceptive methods. The one woman who disagreed simply felt that there were already enough methods currently available. None of the women thought the name "peri-coital contraceptive pill" was an ideal name. One woman said, "what a non-sexy word...'pericoital'...the cousin of the colonoscopy". Another said it made her feel like putting on sweatpants rather than participating in sexual activity. Yet when prompted to suggest new names for this method, women had some difficulty. For the few that responded, popular names that came up in the discussions included "sex pill", "Plan A", "24-hour pill", and other names that focused on the timeframe of use. Many women did not have a response, simply saying it was too new to decide or that someone needs to create a slang term such as "the pill" or "the morning after pill" that would then gain popularity. A few even said they would simply refer to it as "the pill" or "birth control" in conversations and then specify the details about the method if prompted. Figure 1 shows all the names women ultimately chose for the peri-coital contraceptive pill in the exit survey they filled out at the end of the discussions. The size of the term corresponds with its popularity at the end of the discussions. Within each discussion, participants usually chose the same or similar names for the method as they continually up in the conversation. 
Figure 1: Chosen names for the peri-coital contraceptive pill.

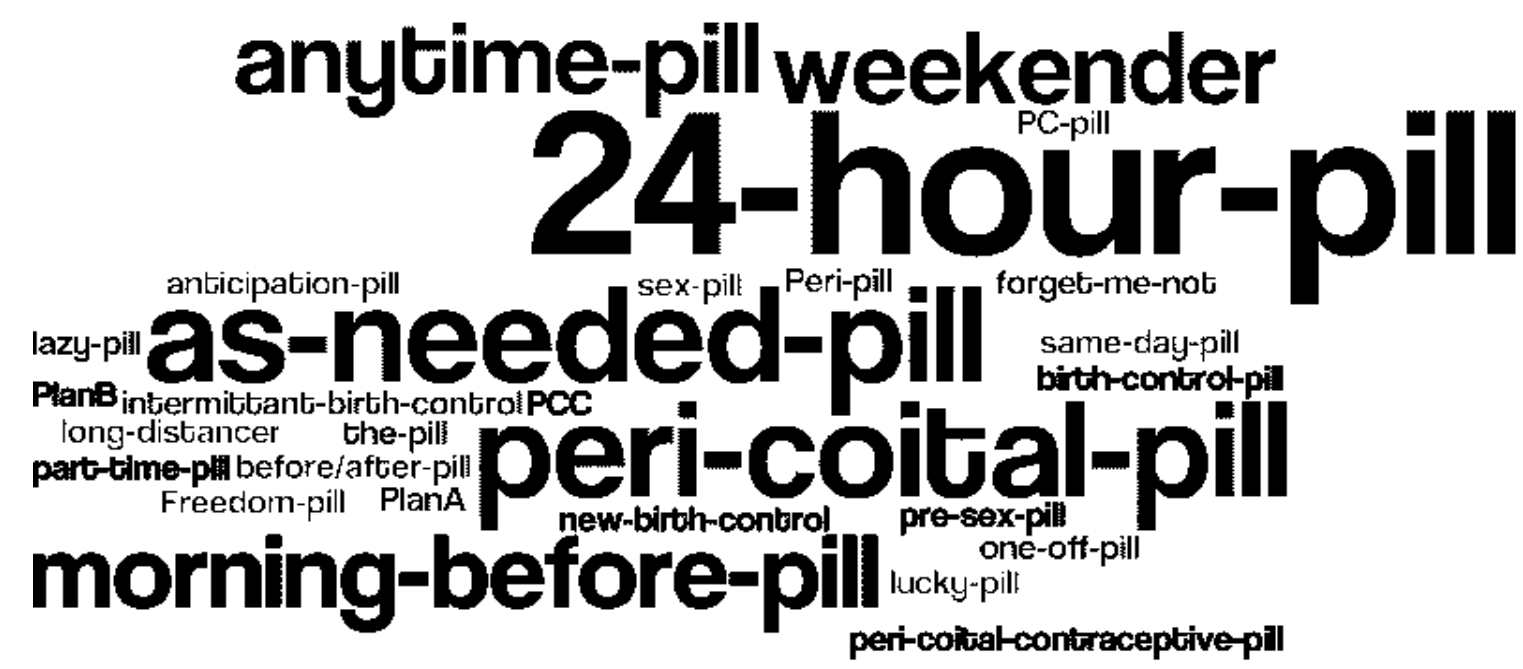

\section{Differentiation of Contraceptive Methods}

Some women found it difficult to name the peri-coital contraceptive pill as they did not feel inspired to offer a creative or unique name. More commonly, women cited difficulty in general when describing ways to differentiate between contraceptive methods, even those that already exist and are commonly used. Women explained that this was part of a larger issue in which current popular methods of contraception had unclear terminology and so introducing yet another method, particularly one that is similar in use and mechanism of action, would introduce more unclear and confusing terminology. Elizabeth in Toronto highlighted this issue when she explained,

I think it's hard because a lot of the terms we use for the other things are fairly euphemistic too so it's not like "the pill" clearly explains what that is and then how it would be different. So it's hard to come up with a name that describes it when none of the others are very descriptive names either. 
This sentiment that current language was unclear was shared by many participants. They repeated that current terminology is "vague" and "confusing". I probed multiple times to explore how this issue could be resolved or what would happen to peri-coital contraception if it is introduced to the Canadian population. Some women still insisted that new language for this method would simply echo the terminology that already exists. As Amy in Ottawa explained,

I don't know if you'll be able to get a really clear lead on the differences between all of them because we tend to be a little vague when we talk about these things and when we say "birth control" we can mean a lot of things. And this would potentially just become one of them so you'd end up with either "intermittent birth control" or you know, the "sex pill" so you'd end up with some other language around it but you'd probably also just end up with very general, I'm on "the pill". Oh which type? I can take whenever, right? Do you have to take the daily one? No I take the one right beforehand, but it might still just get called "the pill"...

Others believed that rather than being lumped into broader categories of "the pill" or "birth control," that it was possible a new name would be introduced with the method. A brand name was a possibility offered by many women in the discussions, especially as a few had referred to OCPs by brand names such as "Alesse" or "Yaz". Yet others like Natalie in Ottawa referred to the peri-coital contraceptive pill in ways that they thought clearly differentiated it from the methods that currently exist, such as a focus on the time frame of use. She explained that the confusion from other methods can be reduced by naming the peri-coital contraceptive pill in way that sets it apart from others.

Well the ones that are already out there, kind of already have their names and some of them are already confusing enough, like people are confusing the "morning-after pill" with the "abortion pill". Like the only one I think that's the clear one is "the pill" like, everyone's totally straight on that. So, you can't really go back in time and, like, change that confusion. I think the only thing you can do moving forward is when you come up with this pill, this new happy pill, give it a name that's so amazing that it makes it stand out! So it's not lumped in, because the other ones, there's already confusion. 
Confusion in current terminology was an opinion shared by the majority of participants. Despite difficulty naming the peri-coital contraceptive pill, women were able to create ways of talking about it by focusing on particular aspects of the method.

\section{Important Factors and Key Aspects}

When asked how women would talk about the peri-coital contraceptive pill with their doctors, they said they would refer to it by the name "peri-coital contraceptive pill" so the doctor knew what they were talking about. They hoped that their doctor would take initiative to talk about this new method but felt that this would not be the case. They would have many questions about the method regarding the efficacy, safety, and protocol for use. Women said they would definitely talk to their friends about it as a positive addition to contraception, especially for those who were taking the daily OCP but did not like this method or often used it inconsistently. Women also said they would talk to their sexual partners about peri-coital contraception, mostly to educate them about the method and how it works. Some women said they would not bother trying to explain the method because they believe men do not understand or care about contraception, but would just refer to it as "birth control". Finally women were quite enthusiastic when asked if they would talk about peri-coital contraception on social media platforms, explaining that they would likely post articles or information in order to educate their online peers.

Participants agreed that the most important aspect of the peri-coital contraceptive pill was the time frame of use and that this aspect made it a unique addition to current contraceptive methods. Because it could be taken before or after an act of sexual intercourse, many women pictured it in the middle of a scale with daily OCPs on one end and emergency contraception on 
the other. One woman even suggested it was a "Plan B advanced" type of method. Margaret in Vancouver described this method as, "kind of both in a way... preventative and damage control in one". Because there was a lot of discussion about context and stigma of emergency contraception, a lot of women liked that this method could be differentiated from emergency contraception because of the option of taking the pill before engaging in sexual activity.

Most of the women were enthusiastic and thought this pill sounded more positive than other methods that are used for pregnancy prevention. Kimberly in Halifax explained,

It sounds funner! I mean we've laughed more about this one than we have any of the other ones. The emergency contraception one is so serious...duh duh duh... and I mean the other ones.... and now we're all like, "ooo peri-coital! Get lucky!" it's kind of fun.

Many women agreed that this method was more fun to talk about because it was related to anticipating sexual activity. Some compared the peri-coital contraceptive pill to the male condom and joked that combined together they could be incorporated into foreplay. When I asked specifically why this pill was so much more positive than other methods which were arguably also used in relation to sexual activity, Emily in Charlottetown replied, "I think the focus on women's choice... like that's what's nice about it [peri-coital contraception]". Many women echoed that choice was the most positive aspect of this method whether it be the choice to take it before or after sex or the choice of deciding to have sex and protecting oneself for that particular act rather than constantly being on a method in case sex does take place.

\section{Packaging the Peri-Coital Contraceptive Pill}

Simone (researcher): Do you think there are any important things that it should say on the packaging?

Kaitlyn: You're welcome. 
Women thought that the best way to package the peri-coital contraceptive pill would be to have it in blister packs that can be separated into individual squares. This would make it easy to carry one at a time to be used either before or after sexual activity. However, there was no consensus in how many pills should be packaged in each blister pack. Women thought anywhere from two to 30 pills could be possible, but this was dependent on the expiration date. Women said it was also dependant on the individual user's preference. Women thought it would be ideal to have a variety of packaging options: a pack of two for a weekend away, packs of 10 or 20 , and then larger club pack sizes if a woman was more sexually active or the pills did not expire for a longer period of time.

I also asked women about the specific appearance of the packaging. Some wanted it to clearly look like medication while others preferred a fun look. All women agreed they wanted the packaging to look discreet. Everyone disliked the bright pink colours, butterflies, or flowers they had seen on other contraceptive pill packaging. Elizabeth in Toronto explained, "I know I'm a woman...I don't need to be reminded I'm a woman because everything I buy is pink. It can be white and that's okay".

Women thought that the packaging should have the brand name of the product as well as information on how to properly take the pill. They also thought that it should clearly say the efficacy when used correctly or perhaps compare its efficacy with other methods on the market. Finally, the most popular opinion was that the packaging should clearly state that this pill did not protect against sexually transmitted infections (STIs). Women thought that this was especially important because this method could be similar to the male condom in use. They did not want younger users to assume that this method could offer both pregnancy and STI prevention and thought that should be very clearly stated. 


\section{Potential Ideal User}

Women had many opinions about who would be the ideal user of the peri-coital contraceptive pill although through discussion they all decided it would be any woman participating in infrequent or irregular sexual intercourse. Some women thought this method would be valuable to younger women who are more likely to have casual sexual encounters although others thought that older women would be just as likely to have these kinds of experiences. Some women thought this method would be less accessible to younger women. Erin in Charlottetown explained,

It goes to availability as well. When we're talking about young people like, we all, almost all, had the same story where we couldn't talk to parents and stuff about getting it so where are they going to get these pills? And then we have expense as well. If you're a young person at home, you don't really have a lot of extra spending money and if you do... "what'd you spend that on honey?".

Some women thought the peri-coital contraceptive pill's use would be more prevalent in single women yet others believed that this method would be great for those in long-distance relationships or those in long-term relationships who were not having as much sex. In Charlottetown and Halifax, women thought this method would be particularly valuable for women whose significant others were oil rig workers in Alberta and returned to the East Coast for one week of each month. Participants thought women in urban areas across Canada would be more likely to use peri-coital contraception, partially because they would likely have access to it before rural populations. Issues like education and socio-economic status were also considered but women said these factors would be influenced by the cost and accessibility of this method in comparison to methods that currently exist and it was difficult to predict when they had so little information about the delivery method. 


\section{Participants' Questions}

Participants asked many questions about the peri-coital contraceptive pill during the discussions. Since this reproductive technology is still in clinical trials, I was unable to answer most of their questions. However, these questions do provide insight into points of confusion, important factors that need to be clearly explained, and other aspects of the method that may arise if it does become available. I've summarized these questions below:

- Once you take the pill, does it take time to "activate" or become effective?

- Is it still effective if used multiple times in one 24 hour period?

- Can it be used often?

- What happens if it is used often and then not at all for a period of time and then used often again?

- How is it different than emergency contraception?

- What side effects could occur from using this method?

- Will you need a prescription or would it be over-the-counter?

- Will it be covered by health insurance?

Women were especially interested in whether you would need to wait a period of time after taking the pill in order for it to become "activated." They joked that this would mean mandatory foreplay, but were also concerned that it may require planning and could not be used in the heat of the moment. They also wondered if you could have multiple sexual encounters in the 24 hours after it had been taken or if this would decrease the efficacy of the method. Women who framed the peri-coital contraceptive pill similarly to emergency contraception did not have these same questions but wondered how this pill was different from LNG-EC and how it would be valuable 
if it could only be taken 24 hours after unprotected sexual intercourse while LNG-EC could be taken much longer.

\section{Potential Concerns}

The questions women asked often resulted in potential concerns they had about pericoital contraception. A number of concerns were associated with the hormone levels in the pericoital contraceptive pill and what kind of side effects could result from using it. These sentiments were echoed in most discussions despite my explanation of the method in which I told each group that the progestin level would be higher than the daily OCP, but lower than LNG-EC and because it comprises progestin, the contraindications and side effects are expected to be similar to those methods. This concern about hormones was framed in two different ways and is illustrated best by the following comments:

I would worry about the hormone level because if it's more than the daily ones and I'm already worried about how much hormones would be in the daily ones, like is this an actual better option? Is this intermittent enough that it's non-hormonal or is it still, because of an upped level, just the same stuff?

This statement by Amy in Ottawa emphasises an over-all concern of hormone-based contraceptive methods which was a view shared by at least one woman in each discussion.

My concern is I were to take that for myself is what does it do to your own menstruation cycle, if you're increasing your hormone levels randomly? Right? Like how would you know if you were pregnant because it might mess up your period and then you don't get your period and you're expecting to, you know what I mean?

This opinion, from Emma in Toronto, emphasises a view that taking a pill intermittently to prevent pregnancy may cause fluctuations in hormone levels and menstruation cycles. Some women were concerned that taking the peri-coital contraceptive pill could induce menstruation; a side effect they believed was associated with taking emergency contraception. Others showed 
concern that taking this method may make the user feel moody or unaroused, side effects women explained are common for users taking the daily OCP and certainly resulting in an emotional state that is not particularly ideal for engaging in sexual activity.

Women said that the peri-coital contraceptive pill would likely be accepted within society. Some thought that this would be more likely if the pill was marketed, similarly to the daily OCP, as a method used prior to intercourse. They did not necessarily believe that this would be the most common use but some were concerned that if it was marketed based on the fact that it can be taken after unprotected sexual intercourse that it would become another method of emergency contraception with a shorter timeframe, therefore a less practical method. Some women were also concerned that the comparison to emergency contraception would result in the stigma and shaming associated with irresponsible casual sexual behaviour in women attaching itself to this new method. Women thought there may be some issues with acceptance of the method because of its obvious association with sex. The following conversation between two women in Halifax demonstrated the possible issue with the new method:

Jennifer: Yeah, there will definitely be a lot of push-back. Yeah, there's really only one reason you'd take it and it's if you're having sex.

Kaitlyn: Heaven forbid the lady wants to have sex!

Unlike other methods that are used for menstrual regulation or alleviating acne, the peri-coital contraceptive pill would only be used for pregnancy prevention. Most women thought this may be considered controversial amongst conservative individuals, but felt that the general public would appreciate a sex-dependent method. Women said the best way to raise awareness about the method would be to disseminate information about it through campaigns or physicians in 
order to educate the population, rather than relying on commercial advertisements which may frame the method in a less than desirable way.

\section{Contraception and Stigma}

Stigma was a recurring theme throughout most of the FGDs in regards to the peri-coital contraceptive pill as well as other contraceptive and abortion methods. Stigma came up multiple times when talking about the nature of the peri-coital contraceptive pill. As I mentioned in potential concerns, women thought that the peri-coital contraceptive pill would be less accepted by society if it was associated with emergency contraception. Women also thought that the pericoital contraceptive pill may be associated with partying and excessive casual sex and referred to it as a "party pill" or a pill to take when you "get lucky". The idea of a party pill was echoed by women in Vancouver, Edmonton, Ottawa, and Charlottetown. However, discussions of stigma came up throughout the FGDs, particularly in Edmonton and Charlottetown where the terms "slut" and "shame" came up numerous times in reference to any of the reproductive health technologies we discussed.

While many of the women self-identified as sex-positive and pro-choice, they agreed that it is difficult to talk about sex because it was rarely an open topic of discussion. Michelle in Vancouver explained why it was often left out of conversation saying, "it's women and sex....it's controversial". Emily in Charlottetown commented that "silence seems to be a repeating theme within sexuality". Eileen in Thunder Bay offered a possible reason why this was an issue in Canada explaining, "there's the aura of shame around it [sex] still that people don't want to talk about birth control because then you're admitting that you're having sex and sex is still considered dirty or whatever to most people". It was difficult to differentiate whether 
the discussions about sex and stigma were the personal views of participants or simply observations of views popularized by society.

\section{Contraception and Men}

Another overarching theme in the FGDs was men's lack of knowledge of, and opinions about contraception. Women agreed they would indeed talk to their male sexual partners about contraception although many expressed that men really did not understand the topic. Natasha in Thunder Bay explained, "I think I'd have to explain it to my partner to tell him what it [emergency contraception] is. I don't think- if I said 'Plan B' or the 'morning after pill', he'd be like....the morning after what? I think I'd just have to spell it out". Many expressed that men were not often included in conversations of contraception and the women felt their partners did not care which method of contraception they used, as long as they were on "something". They disliked this apparent apathy and thought that men should be part of conversations about contraception. As Jennifer explained, "if men are having sex with women, it is also their responsibility to be, like, informed about birth control". This demonstrates the shared opinion that men need more education about contraception.

Some women thought that the peri-coital contraceptive pill would be a great way to involve men in the conversation. Lauren in Toronto thought that it could make contraception "more of a shared experience" because if it was marketed similar to condoms then her partner could pick it up for her at the pharmacy. Anna in Halifax thought that it would be a "great thing" if men knew this method was available to their partners. Some expressed frustration that there were no contraceptive methods for men apart from the condom. However, many women wanted 
to be responsible for their own contraception and preferred to educate men about methods so they could participate in more conversations about them.

When asked why they thought men knew so little about contraception, women explained that it was likely a result of inadequate sex education. Emily in Charlottetown explained, I think the lack of good quality sex education is a big issue so I think if we had really good quality sex education when people were in middle school and high school, we would have fewer problems later. But I really- I think it needs to be directed at men as well. I find a lot of sexuality topics are directed at women and there are women's sexual health centres. There's just a lot for women but I think a lot more for men would help women.

Most of the participants agreed with this explanation. They did not perceive men's ignorance on the topic to stem from the fact that they it was not their issue but rather that they were uneducated and had no explicit opportunity to discuss methods and become a part of a conversation that is heavily focused on women and their physicians.

\section{Misperceptions about Contraception}

The final over-arching theme of the FGDs can be broadly categorized as misconceptions or misinformation about contraception. These were particularly evident when I introduced the peri-coital contraceptive pill. After I told them about the method, many had questions about the efficacy, such as Hannah in Charlottetown who asked if the efficacy I explained for the method was also in conjunction with pulling out. I clarified that an efficacy rate is based on the correct use of a method alone and not in combination with others. Ashley in Edmonton was also concerned about the efficacy of this new method asking,

I'm just curious about what its efficacy would be... with alcohol. Because to me something like that, and maybe I'm just being judgmental, would be "we're going out Friday night, I might hook up with somebody, I'm going to take the pill”. If you're going 
out, you're probably going to a bar, you're probably drinking quite a bit. How effective is it going to be mixed with alcohol?

This question was also asked by other women who were concerned about alcohol use, particularly those who had associated the peri-coital contraceptive pill with partying. I was surprised by this question since no one inquired about the efficacy of LNG-EC or the daily OCP when taken with alcohol and I had clearly explained that the active hormone, progestin, was found in both of those methods as well. Finally in discussion of the peri-coital contraceptive pill's potential concerns Sophie in Thunder Bay was apprehensive about the method because of fluctuations in hormones in your level that could be, "actually damaging your hormonal system, or like the lining to your uterus, or the way your eggs come out or anything like that". While this is associated with the overall concern that hormones were somehow unsafe and damaging to the female body, this quote demonstrates that the actual mechanism of action for contraceptive methods is very unclear.

A greater misperception about hormones that was demonstrated by the FGDs is that no one acknowledged that estrogen, not progestin, is the hormone that causes the most significant side effects experienced by OCP users. Even though I explained that the peri-coital contraceptive pill was a progestin-only contraceptive method, these women were still concerned about side effects that have been associated with the use of a contraceptive method containing estrogen. This suggests that the women in the FGDs do not differentiate between hormones or perhaps do not understand that there are differences between them. Finally, despite explaining the similarities of this new method to the methods that currently exist, they had concerns about the peri-coital contraceptive pill that simply did not exist for other methods. It is unclear as to why the concerns and questions raised pertained mostly to the peri-coital contraceptive pill; however, 
this demonstrates the need to clarify issues surrounding the function of such a contraceptive method.

\section{Canadian Reproductive Health Issues}

The most common reproductive health issue described by women was the lack of sexual and reproductive health education in the country. This in turn affects access as many women do not know about available methods and therefore lack knowledge about methods that may suit their needs better than the standard OCP or condom. Sexual and reproductive health education, particularly in schools was a popular issue participants raised, especially as few women had positive or remarkable experiences with their sex education. Michelle in Vancouver explained why stigma influenced sexual and reproductive health education in Canada by saying,

It seems like that's sort of like this subversive hand of stigma. When we can't talk about it $[\mathrm{sex}]$ in an educating and mature way... kids talk about it... what celebrities are doing and it's misinformation and it's wrong... and that's what they're learning.

The issue of education was determined by many women to be a larger issue of a lack of space in which to talk about sexual and reproductive health as it is often stigmatized. Margaret in Vancouver echoed this issue of stigma and the inability for society to have conversations about sex as she explains, “as long as stigma is there, people just aren't going to feel open to talking about it". That many women felt this same way leads to a circular issue: sex is a stigmatized topic so people do not want to talk about it yet if no one talks about sex it continues to be stigmatized. Creating spaces to talk about sex in a mature and educational way was the solution offered by many of the women. The Thunder Bay FGD coincided with the release of the new sexual health curriculum in Ontario and sparked further conversation about education. Lisa in 
Thunder Bay made a valuable observation about the complexity of sex education and again, the importance of conversation:

Well we just revised the sexual health curriculum and that's a whole other topic of conversation... we could sit around and talk about that for hours but I think we need to focus less on the mechanics of things and more on talking to young people about relationships and sort of like, the dynamics of relationships and things like negotiation and um, responsibilities and shared responsibilities and things like that...because let's face it, like especially with the internet today, you can go online and you can learn about the different options for contraception. Most young people are probably more comfortable going online if we give them credible websites to go to...A better use of our time is going in and talking to young people about their relationships and how to negotiate what you want and how to talk to the person you want to be intimate with about protecting yourself, me protecting me, you protecting you, and those kinds of things.

As this quote illustrates, it is true that information about contraception is important to know but there are also other conversations regarding sex that are completely ignored by school curricula and are arguably just as important.

Reproductive health issues were diverse in discussions as women in each city specified different issues that affect their area. The issue of abortion access came up in the Charlottetown discussion as Emily explained, “I know I mentioned on PEI but PEI's not the only place where that's difficult. I know that New Brunswick is too but even in rural areas in Canada...”. Both Charlottetown and Ottawa participants explained to me that high rates of infertility had been documented in their areas. Women in Halifax, Toronto, and Vancouver described themselves as fortunate since they had more access to sexual and reproductive health services compared to smaller and more rural areas around them and also mentioned Northern Ontario and Eastern Canada have difficulty accessing these services. However, these women thought improvements to sex education in their cities would be beneficial. Women in Ottawa described high rates of STIs in the Ottawa area which is an issue for sexually active individuals. Women in Thunder Bay described an "endemic" of Hepatitis C in their area, affecting much of the population. 
Finally, women in Thunder Bay and Charlottetown described the need for more reproductive health services, particularly an issue in Charlottetown where there is currently no designated sexual health clinic. 


\section{Chapter 6: Discussion}

Clinical trials are currently underway and although the peri-coital contraceptive pill has yet to be (re)introduced, a body of research examining the need and desire for this method exists. Studies exploring repeated post-coital use of LNG-EC have demonstrated that small subsets of women globally use post-coital contraception as their preferred method of pregnancy prevention (Keesbury et al., 2011; Lerkiabundit \& Reanmongkol, 2000; Opuku \& Kwaununu, 2011). In Kenya and Thailand, there is evidence that women are purchasing LNG-EC products at least once a week as a method of pregnancy prevention (Keesbury et al., 2011; Lerkiabundit \& Reanmongkol, 2000).

Researchers have also conducted studies to explore perceptions of a hypothetical pericoital contraceptive pill. Three studies examined women's opinions of a hypothetical "ondemand"oral contraceptive pill (Foster, Biggs, Grossman, \& Schwarz, 2013; Cover et al., 2013; Raymond, Halpern, \& Lopez, 2014). The first was a study in the US which explored women's perceptions of the peri-coital contraceptive pill through surveys to women in abortion clinics. The second study explored women's and men's perceptions of the method in Uganda and India through the use of focus group discussions and interviews. Finally, the third study also used surveys to gauge individuals' reactions to the method in Nigeria and Kenya. All three studies found positive reactions to the peri-coital contraceptive pill with nearly half of all participating women showing an interest in using the new method (Foster et al., 2013; Cover et al., 2013; Raymond et al., 2014). Women in Kenya and Nigeria who had used LNG-EC before were particularly likely to consider the peri-coital contraceptive pill as a primary method of contraception (Foster et al., 2013; Cover et al., 2013; Raymond et al., 2014). 
Collectively, these studies demonstrated that interest in the method was associated with factors such as difficulty obtaining prescriptions for contraception, recent participation in unprotected sexual intercourse, and prior use of other contraceptive methods (Foster et al., 2013; Cover et al., 2013; Raymond et al., 2014).The advantages listed by women were that the method would be easier to remember, could be taken only as needed, could be taken before or after sexual intercourse and that it would be especially beneficial to those participating in infrequent sexual intercourse (Foster et al., 2013; Cover et al., 2013; Raymond et al., 2014). Concerns about a hypothetical peri-coital contraceptive method included the consequences of forgetting to take the pill within the time frame, side effects, and the possibility that the method would be less effective than other contraceptive methods.

These advantages and concerns are consistent with the findings of this Canadian study. My results indicate Canadian women are also enthusiastic about the peri-coital contraceptive pill and cited many of the same reasons why this method was appealing to them. The participants also had similar concerns about the method and were curious to learn more about the peri-coital contraceptive pill. Although none of the participants detailed experiences of using LNG-EC as "regular" contraception, women were interested in the peri-coital contraceptive pill because it would be sex-dependent and liked that it would be associated with choice. My study is slightly different to other studies dedicated to the peri-coital contraceptive pill as it is the first to concentrate specifically on the naming of the method and the language women use to talk about the method. These findings focused on naming and framing peri-coital contraception are consistent with the findings from the study which I conducted in February 2013 with University of Ottawa students, which is not surprising as it was the pilot study for this project. The findings 
of this study demonstrate that there is a demand for more options for Canadian women seeking contraception and that peri-coital contraception would be a valuable addition to current methods.

An important theme from this study is the importance of the clinician-patient relationship. Contraceptive counselling is a mainstay of reproductive health service delivery and studies have demonstrated that it is indeed successful in educating patients about available contraceptive options. In the specific context of family planning clinics research has shown that patients who have a more positive experience at the visit have more positive opinions and attitudes towards their contraceptive method of choice (Rosenburg, Waugh, \& Burnhill, 1998; Forrest \& Frost, 1996). By providing information about available methods, contraceptive counselling better prepares women to choose the method that best fits their lives. A 2004 Canadian study surveyed 649 women across the country who were filling a prescription for OCPs at Shopper's Drug Mart stores (Gaudet, Kives, Hahn, \& Reid). The study found that women who had received contraceptive counseling from their physicians were more likely to understand and react better to potential side effects than those who had not received counseling. Those who received counseling were also more aware of what to do in the case of missed pills than those who did not (Gaudet et al., 2004). The study also found evidence of misinformation about contraceptive methods, but it is unclear if this misinformation originated from conversations with physicians or the influence of media.

The findings of my study show that women would like to learn more about peri-coital contraception from their physicians. Women indicated they learned much of their knowledge of contraception from personal online research and when learning about the peri-coital contraceptive pill, they explained they would expect their physician to introduce them to new contraceptive methods or at least be able to answer questions and provide more information. 
Thus, once available, efforts should be made to include this method in contraceptive counseling guidelines in Canada. This could include the addition of information about the peri-coital contraceptive pill in the Canadian Contraception Consensus, a clinical practice guideline developed by the Society of Obstetricians and Gynaecologists of Canada.

Finally, a prevailing theme within the FGDs was the notion of social stigma surrounding women and sex. Overall there was no stigma associated with OCPs, although some women were concerned there was stigma associated with LNG-EC use. Stigma arose in conversation when discussing the over-arching reason for contraceptive use: women engaging in non-procreative sexual activity. Social stigma "refers to an attribute that is deeply discrediting" (Goffman, 1991, p.3). This is based on what society deems a discrediting attribute and results in stereotypes and discrimination. That women having non-procreative sex was associated with stigma was not necessarily surprising but certainly demonstrated the complexity of discourses about sex. References to sexual intercourse are pervasive in social media and popular culture. Participants could all provide examples of depictions of sex in these spaces. Yet when asked for references about contraception in sexual scenes, the responses were scarce. Women noted that there is silence surrounding contraceptive use in sex and it appears that this silence is largely created by a stigma surrounding women's sexual experiences. .

Stigma towards female sexuality was also demonstrated in other ways. Despite the majority of women sharing sex-positive attitudes in the FGDs, all were sensitive to the stigma that exists regarding women and sex. This was reflected in the discourses used to talk about LNG-EC, mifepristone, and the peri-coital contraceptive pill. Women joked about the ways society disapproves of women having sex yet some still discussed concerns about peri-coital contraception in relation to partying, "hooking up", and being a "slut". Many of the women 
agreed that a lack of comprehensive sex education was a reproductive health issue in Canada. Not only are the fundamentals of sex important but also more abstract concepts like issues of consent and communicating to ensure safe and pleasurable sex. I believe this stigma surrounding women's sexuality prevents conversations about contraception from happening but obviously does not prevent sex from occurring. These findings demonstrate the need to create a space where one can speak frankly about sex, encompassing all aspects of sex, particularly contraception, and not just the "sexy" parts presented in popular media.

The peri-coital contraceptive pill may aid in creating spaces to speak frankly about sex. Women were enthusiastic to learn that the method was sex-dependent and despite concerns that the peri-coital contraceptive pill would be associated with "hooking up" or partying, women emphasized positive aspects of the method as well. Women liked that the peri-coital contraceptive method focused on choice; women can when to take the contraceptive method and women can choose to have sex. Because the method is sex-dependent and would only be used to prevent pregnancy, there is an opportunity to frame the peri-coital contraceptive pill as a sexpositive method.

This study demonstrates that language is a really important aspect to consider when introducing a reproductive technology. Women talked about peri-coital contraception by focusing on the unique aspects of the method and by comparing and contrasting it to current available contraceptive methods. Particular aspects they highlighted about this method were that it could be taken before or after sex and that it was sex-dependent. This was evident in the names they ultimately chose for the peri-coital contraceptive pill including "as-needed pill", "24-hour pill", and "sex pill". The more women learned about the method and creating new terms to talk about it, the more eager they were about having this method as a potential option for 
contraceptive use. Thus, this study establishes that we must thoughtfully create language with which to talk about the peri-coital contraceptive pill in order to enhance uptake, acceptability, and cultural resonance.

\section{Positionality}

As a researcher interested in individuals' experiences and language related to contraceptive practices, it was important to consider positionality. There are multiple truths as there are multiple experiences and it was important to be mindful throughout the study that I am not an authority on what it is to be a woman. Therefore I continually recognized my background, position, and assumptions while doing research in the process of reflexivity. As FGD facilitator, I also worked with participants to try to create more of a mutual collaborative research project (Hesse-Biber \& Yaiser, 2004). As research is value-laden and power structures exist, it is important that I continually acknowledged these dynamics to prevent maintaining any hierarchies that exist within society.

As a contraceptive using Canadian woman who is 24 years old, I have my own personal experiences with heterosexual contraceptive practices and my own language and terminologies with which to discuss them. Thus I can define myself as an "insider" in the study of women's experiences (Tuhiwai Smith, 2012). However, I am also an "outsider”, as the knowledge and expertise I have developed in the field of contraception surpasses many other women's knowledge. Therefore, it was imperative that I validated other's experiences and avoided becoming an "expert" in the FGDs. I was constantly conscious of my role as a facilitator in the FGDs and made sure I allowed the participants to control the direction the conversations took so as to influence the discussion as little as possible. However, I was responsible for guiding the 
FGDs, keeping the participants on topic within the allotted timeframe for discussion and to answer any questions about contraception they may have had.

\section{Limitations}

The qualitative method used in this study was essential for the in-depth analysis of the language Canadian women used to talk about contraceptive and abortion technologies and how this language would influence the way they talk about peri-coital contraception. This methodology is not intended to be representative or generalizable to a larger population. The sample size was small and relied primarily on women's interest in the subject and willingness to participate in the study. Therefore, many women identified as sex-positive and pro-choice and this may have influenced the FGD content. The geographical locations for the study were indeed chosen purposefully. However, not all provinces were represented and none of the territories were included. While the territories were excluded primarily for practical reasons such as avoiding the lengthy process of applying for a research license, it is a limitation nonetheless. Because I am not bilingual, this study was only conducted in English. As a result, the findings of this study are limited to the English language and fail to encompass both of Canada's official languages.

\section{Future Directions}

Due to the limitations of my study, future studies are encouraged to explore the language Canadian women use to talk about peri-coital contraception by engaging with women in other provinces and territories. Further studies in Canada could benefit from more geographically diverse samples to gain more insight into the language differences across Canada. Future 
research should also explore marginalized communities, including trans* individuals' perceptions and attitudes of the peri-coital contraceptive pill as a convenient, sex-dependent hormonal method that may be valuable to this community as well.

This project is part of a large-scale multi-national study dedicated to developing consensus terms in English and French that will be conducted over next few years. The English portion of the study will include Australia, Canada, the UK, and the US, and the French component of the study will include Canada, France, and Tunisia. These countries were purposively chosen to represent several language contexts and leverage existing research collaborations. My study exploring the language Canadian women use to talk about peri-coital contraception serves as the pilot of this multi-national study as well as the Canadian English component. 


\section{Chapter 7: Conclusion}

The emergence of the peri-coital contraceptive pill, a pill that can be taken 24 hours before to 24 hours after an act of sexual intercourse, could be a valuable addition to current contraceptive methods in Canada. Yet it is particularly important when introducing a new method to potential users to consider the language and frameworks with which to talk about them. Clear, concise language is required, particularly for women to talk and ultimately think about peri-coital contraception. This thesis aimed to explore how Canadian women talk about existing methods of contraception, how these discourses influences the way they would talk about peri-coital contraception, as well as any perceptions and concerns they may have about this method. Situated within a context of reproductive justice and based on a belief in the importance of having many available methods of contraception for women to choose from, this thesis also draws on the concepts of social constructionism to highlight the importance of language when considering the creation of terminologies surrounding emerging reproductive technologies.

Through the use of FGDs, I was able to explore the ways in which women talk about current reproductive health technologies and how this language influences the way they talk about peri-coital contraception. The findings of this study demonstrate that peri-coital contraception would indeed be a valuable addition to current contraceptive methods. Names for the peri-coital contraceptive pill were similar in nature to names for current contraception although women tried to focus on the time frame or aspects that makes it a unique method. Comparisons to LNG-EC and the daily OCP demonstrate that Canadian women frame and talk about emerging reproductive technologies using language related to current contraception. Misperceptions about current contraception and an overall stigma regarding sexual and reproductive health were salient themes within the FGDs. 
Because the method is still in clinical trials, this study gathered perceptions and opinions about the peri-coital contraceptive pill without external influence from media or the medical field. It is valuable to collect this information prior to the release of this new contraceptive method in order to gain insight into the ways peri-coital contraceptive could be effectively introduced to Canadian women. In conjunction with parallel research in other countries, we can hope to create clear, consensus terms in English and French with which to introduce the pericoital contraceptive pill to potential contraceptive users. 


\section{$\underline{\text { References }}$}

Andrews, T. (2012). What is social constructionism? Grounded Theory Review: an International Journal, 11(1). Retrieved from http://groundedtheoryreview.com/2012/06/01/what-issocial-constructionism/

Backhouse, C. (1992). The contemporary women's movements in Canada and the United States: an introduction. In C. Backhouse \& D.H. Flaherty (Eds.), Challenging times: The women's movement in Canada and the United States (pp. 3-20). Montreal, QC: McGill University Press.

Ball, M. J. (1975). Obstacles to progress in family planning [Article Reprint] In B. Schlesinger (Ed.), Family planning in Canada: a source book (pp. 22-28). Toronto, ON: University of Toronto Press.

Belenky, M. F., Clinchy, B. M., Goldberger, N. R., \& Tarule, J. M. (2008). Procedural knowledge: separate and connected knowing. In A. M. Jaggar (Ed.), Just methods: an interdisciplinary feminist reader (pp. 235-246). Boulder, CO: Paradigm Publishers.

Berger, M. T., \& Guidroz, K. (Eds.). (2009). The intersectional approach: transforming the academy through race, class \& gender. Chapel Hill: The University of North Carolina Press.

Berger, P. L. (1966). The Social Construction of Reality. New York NY: Doubleday \& Company Inc.

Bouma, G. D. \& Bouma, W. J. (1975). Fertility Control: Canada's Lively Social Problem. Don Mills, Ontario: Longman Canada Limited.

Bourhis, R. Y., Roth, S., \& MacQueen, G. (1989). Communication in the hospital setting: a survey of medical and everyday language use among patients, nurses and doctors. Soc. Sci. Med., 28(4), 339-346.

Bowker, L. (2001). Terminology and gender sensitivity: a corpus-based study of the LSP of infertility. Language in Society, 30, 589-610.

Brooks, A., \& Hesse-Biber, S. N. (2007). An invitation to feminist research. In S. N. HesseBiber \& P. L. Leavy (Eds.), Feminist Research Practice (Chapter 1, pp. 1-26). Thousand Oaks: Sage Publications, Inc.

Burr, V. (2003). Social Constructionism ( $2^{\text {nd }}$ ed.). New York: Routledge.

Castro, C. M., Wilson, C., Wang, F. \& Schillinger, D. (2007). Babel babble: physicians' use of unclarified medical jargon with patients. American Journal of Health Behaviour, 31(1), $85-95$. 
Chang-hai, He, Yong-en, Shi, Ding-ling, Liao, Yue-hua, Zhu, Jian-qiu, Xi, Matlin, S.A., ...\& Van Look, P. F.A. (1990). Comparative cross-over pharmacokinetic study on two types of postcoital contraceptive tablets containing levonorgestrel. Contraception, 41(5), 557567.

Chang-hai, He, Yong-en, Shi, Jian-qiu, Xu \& Van Look, P. F.A. (1991). A multicenter clinical study on two types of levonorgestrel tablets administered for postcoital contraception. International Journal of Gynecology and Obstetrics, 36, 43-38.

Coeytaux, F., Wells, E. S., \& Westley, E. (2009). Emergency contraception: have we come full circle? Contraception, 80, 1-3. doi:10.1016/j.contraception.2009.03.019

Cover, J. K., Drake, J. K., Kyamwanga, I. T., Turyakira, E., Dargan, T., Kumakech, E. \& Harner-Jay, C. (2013). Consumer perspectives on a pericoital contraceptive pill in India and Uganda. International Perspectives on Sexual and Reproductive Health, 39(4), 195204. doi: $10.1363 / 3919513$

Crawford, Sue E. S., \& Ostrom, Elinor (1995). A grammar of institutions. American Political Science Review, 89(3), 582-600.

de Oliveira, D. L.. (2011). The use of focus groups to investigate sensitive topics: an example taken from research on adolescent girls' perceptions about sexual risks. Ciência \& Saùde Coletiva, 16(7), 3093-3102.

Dickson, G. L. (2008). Metaphors of menopause: the metalanguage of menopause research. In A. M. Jaggar (Ed.), Just methods: an interdisciplinary feminist reader (pp. 151-163). Boulder CO: Paradigm Publishers.

Dodd, D. (1983). The Canadian birth control movement on trial, 1936-1937. Social History, XVI (32), 411-428.

Fals-Borda, O. (2006). Participatory (action) research in social theory: origins and challenges. In P. Reason \& H. Bradbury (Eds.). Handbook of action research (pp.27-37). London: Sage Publications Ltd.

Forrest J. D. \& Frost J. J. (1996). The family planning attitudes of low-income women. Family Planning Perspectives, 28(6), 246-277.

Foster, D. G., Biggs, M. A., Grossman, D., \& Schwarz, E. B. (2013). Interest in a pericoital pill among women in family planning and abortion clinics. Contraception, 88, 141-146.

Foucault, M. (1978). The history of sexuality, Volume 1: an introduction. New York: Pantheon Books. 
Frost, J. J., Singh, S., \& Finer, L. B. (2007). Factors associated with contraceptive use and nonuse, United States, 2004. Perspectives on Sexual and Reproductive Health, 39(2), 9099. doi: $10.1363 / 3909007$

Gaudet, L.M., Kives, S., Hahn, P. M., \& Reid, R. L. (2004). What women believe about oral contraceptives and the effect of counseling. Contraception 69, 31-36.

Ginsburg, F. D. \& Rapp, R. (Eds.). (1995). Conceiving the new world Order: The global politics of reproduction. Berkeley: University of California Press.

Goffman, E. (1991). Stigma. New York, NY: Simon \& Schuster.

Grimes, D. A., \& Stuart, G. (2010). Abortion jabberwocky: the need for better terminology. Contraception, 81, 93-96. doi: 10.1016/j.contraception.2009.09.005

Hadlow, J. \& Pitts, M. (1991). The understanding of common health terms by doctors, nurses and patients. Soc Sci Med, 32(2), 193-196.

Hall, S. (1997). The Work of Representation. In S. Hall (Ed.), Representation: Cultural representations and signifying practices. London: Sage Publications Ltd.

Halpern, V., Raymond, E. G., \& Lopez, L. M. (2010). Repeated use of pre- and postcoital hormonal contraception for prevention of pregnancy. Cochrane Database of Systematic Reviews, 12, 1-50. DOI: 10.1002/14651858.CD007595.pub2

Hennink, Monique M. (2014). Focus group discussions: Understanding qualitative research. New York, NY: Oxford University Press.

Hesse-Biber, S. N., \& Yaiser, M. L. (Eds.). (2004). Feminist perspectives on social research. New York, NY: Oxford University Press.

Jensen, J. T. (2011). The future of contraception: innovations in contraceptive agents: tomorrow's hormonal contraceptive agents and their clinical implications. American Journal of Obstetrics \& Gynecology, S21-S25. doi: 10.1016/j.ajog.2011.06.055

Kapoor, I. (2005). Participatory development, complicity and desire. Third World Quarterly, 26(8), 1203-1220.

Kaunitz, A. M. (2004). Enhancing oral contraceptive success: the potential of new formulations. American Journal of Obstetrics \& Gynecology, 190, S23-29. doi:10.1016/j.ajog.2004.01.062

Keesbury, J., Morgan, G., \& Owino, B. (2011). Is repeat use of emergency contraception common among pharmacy clients? Evidence from Kenya. Contraception, 83, 346-351. doi:10.1016/j.contraception.2010.08.010 
Kindon, S., Pain, R., \& Kesby, M. (Eds.) (2007). Participatory action research approaches and methods: Connecting people, participation and place. New York, NY: Routledge.

Kluchin, R. M. (2009). Fit to be tied: Sterilization and reproductive rights in America, 19501980. New Jersey: Rutgers University Press.

Lazar, M. M. (2007). Feminist critical discourse analysis: articulating a feminist discourse praxis. Critical Discourse Studies, 4(2), 141-164. DOI: 10.1080/17405900701464816

Leavy, P. L. (2007). The practice of feminist oral history and focus group interviews. In S. N. Hesse-Biber \& P. L. Leavy (Eds.). Feminist research practice (pp. 223-248). Thousand Oaks: Sage Publications, Inc.

Lerkiatbundit, S. \& Reanmongkol, W. (2000). Use of $0.75 \mathrm{mg}$ levonorgestrel for postcoital contraception in Thailand. Journal of Clinical Pharmacy and Therapeutics, 25, 185-190.

Mackenzie, C. J. G. (1972). Birth control in Canada. A commissioned paper to the Community Health Centre Project. Vancouver, BC: Canadian Public Health Association.

Mackenzie, C. J. G. (1975a). Is family planning in rural areas adequate? [Article reprint] In B. Schlesinger (Ed.), Family planning in Canada: A source book (pp. 16-21). Toronto, ON: University of Toronto Press.

Mackenzie, C. J. G. (1975b). Some mythology of birth control. In B. Schlesinger (Ed.), Family planning in Canada: A source book (pp. 29-33). Toronto, ON: University of Toronto Press.

Martin, E. (1991). The egg and the sperm: How science has constructed a romance based on stereotypical male-female roles. Signs: Journal of Women in Culture and Society, 16(3), 485-501.

McLaren, A. \& McLaren, A. T. (1997). The bedroom and the state: The changing practices and politics of contraception and abortion in Canada, 1880-1997 ( $2^{\text {nd }}$ ed.). Toronto, ON: Oxford University Press.

Pruitt, S. L., \& Mullen, P. D. (2005). Contraception or abortion? Inaccurate descriptions of emergency contraception in newspaper articles, 1992-2002. Contraception, 71, 14-21. doi:10.1016/j.contraception.2004.07.012

Rainwater, L. (1967). And the poor get children: Sex, contraception and family planning in the working class. Chicago, IL: Quadrangle Paperbacks.

RamaRao, S., Sitruk-Ware, R., \& Townsend, J. W. (2008). New vistas in contraceptive technology. Gender and Development, 16(2), 327-344. DOI: $10.1080 / 13552070802120525$ 
Ratcliff, K. S. (2002). Women and health: Power, technology, inequality, and conflict in a gendered world. Toronto: Allyn and Bacon.

Raymond, E. G., Halpern, V., \& Lopez, L. M. (2011). Pericoital oral contraception with levonorgestrel. Journal of Obstetrics \& Gynecology, 117(3), 773-681. Doi: 10.1097/AOG.0b013e318209dc25

Raymond, E. G., Shochet, T., Drake, J. K. \& Westley, E. (2014). What some women want? Ondemand oral contraception. Contraception, 90, 105-110. http://dx.doi.org/10.1016/j.contraception.2014.04.008

Robbins, W., Luxton, M., Eichler, M., \& Descarries, F. (Eds.). (2008). Minds of our own: Inventing feminist scholarship and women's studies in Canada and Quebec, 1966-76. Waterloo, ON: Wilfred Laurier Press.

Rosenburg M. J., Waugh M. S. \& Burnhill, M. S. (1998) Compliance, counseling and satisfaction with oral contraceptives: a prospective evaluation. Family Planning Perspectives, 30(2), 89- 104.

Ross, L. \& Roberts, L. (2006). Reproductive justice. Off Our Backs, 36(4), 10-11.

Ross, L. (2006). Understanding reproductive justice: transforming the pro-choice movement. Off Our Backs, 36(4), 14-19.

Scott, J. (1991). The evidence of experience. Critical Inquiry, 178(3), 773-97.

Sundstrom, B. (2012). Fifty years on "the pill": a qualitative analysis of nondaily contraceptive methods. Contraception, 86, 4-11. doi:10.1016/j.contraception.2011.10.016

Swinton, C. (1975). Population and family planning: an overview. In B. Schlesinger (Ed.). Family planning in Canada: A source book (pp. 9-15). Toronto, ON: University of Toronto Press.

Trussell, J. (1991). Methodological pitfalls in the analysis of contraceptive failure. Statistics in Medicine, 10, 201-220.

Tuhiwai Smith, L. (2012). Decolonizing methodologies. New York: Zed Books.

Vickers, J. (1992). The intellectual origins of the women's movements in Canada. In C. Backhouse \& D. H. Flaherty (Eds.). Challenging times: The women's movement in Canada and the United States (pp. 39-60). Montreal, QC: McGill University Press.

Wadsworth, Y. (1998). What is participatory action research? Action Research International, Paper 2. Retrieved from www.scu.edu.au/schools/gcm/ar/ari/p-ywadsworth98.html 
Weitz, T .A., Foster, A., Ellertson, C., Grossman, D., \& Stewart, F. H. (2004). “Medical” and "surgical" abortion: rethinking the modifiers. Contraception, 69, 77-78. doi:10.1016/j.contraception.2003.08.017

Wilkinson, S. (1998). Focus groups in feminist research: power, interaction, and the coconstruction of meaning. Women's Studies International Forum 21(1), 111-126.

Wilkinson, S. (1999). Focus groups. Psychology of Women Quarterly, 23(2), 221-244.

World Health Organization (WHO) Task Force on Postovulatory Methods of Fertility Regulation (2000). Efficacy and side effects of immediate postcoital levonorgestrel used repeatedly for contraception. Contraception, 61, 303-308.

Wynn, L. L. \& Foster, A. M. (2012). The birth of a global reproductive health technology: an introduction to the journey of emergency contraception. In A. M. Foster \& L. L. Wynn, (Eds.). Emergency contraception: The story of a global reproductive health technology. New York, NY: Palgrave MacMillan.

Wynn, L. L., Foster, A. M., \& Trussell, J. (2009). Can I get pregnant from oral sex? Sexual health misconceptions in e-mails to a reproductive health website. Contraception, 79, 91-97. doi:10.1016/j.contraception.2008.08.009

Wynn, L. L., Foster, A. M., \& Trussell, J. (2010). Would you say you had unprotected sex if ...? Sexual health language in emails to a reproductive health website. Culture, Health \& Sexuality, 12(5), 499-514.doi: 10.1080/1369 1051003653631

Wynn, L., \& Trussell, J. (2005). The morning after on the internet: usage of and questions to the emergency contraception website. Contraception, 72, 5-13.

doi:10.1016/j.contraception.2005.02.007 